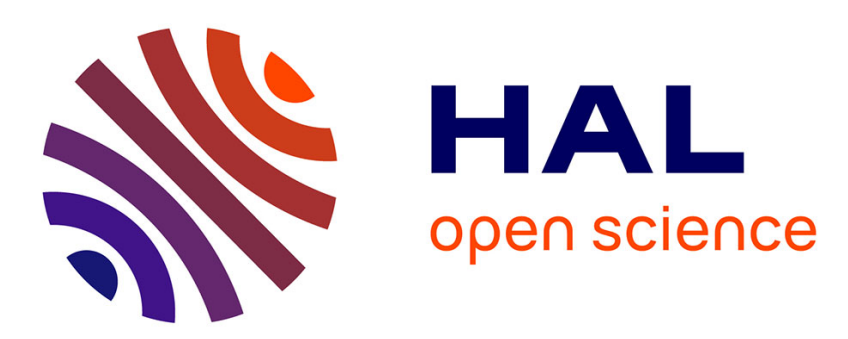

\title{
Term structure of interest rates: modelling the risk premium using a two horizons framework \\ Georges Prat, Remzi Uctum
}

\section{To cite this version:}

Georges Prat, Remzi Uctum. Term structure of interest rates: modelling the risk premium using a two horizons framework. Journal of Economic Behavior and Organization, 2021, 182, pp.421-436. 10.1016/j.jebo.2019.09.006 . hal-03319099

\section{HAL Id: hal-03319099 \\ https://hal.science/hal-03319099}

Submitted on 11 Aug 2021

HAL is a multi-disciplinary open access archive for the deposit and dissemination of scientific research documents, whether they are published or not. The documents may come from teaching and research institutions in France or abroad, or from public or private research centers.
L'archive ouverte pluridisciplinaire HAL, est destinée au dépôt et à la diffusion de documents scientifiques de niveau recherche, publiés ou non, émanant des établissements d'enseignement et de recherche français ou étrangers, des laboratoires publics ou privés. 


\title{
Term structure of interest rates: modelling the risk premium using a two horizons framework
}

\author{
Georges Prat ${ }^{\mathrm{a}}$ and Remzi Uctum ${ }^{\mathrm{b}}$
}

\begin{abstract}
We propose a two-horizon interest rate term structure model where the maturity of the riskless rate is the one of the debt security whose duration equals investor's desired horizon. Our framework thus relaxes the usual assumptions of the literature that the riskless rate is unchangingly the short period rate. A representative investor compares at each of the 3and the 6-month horizons the risk premium offered by the market and the one they require to take a risky position, the latter premium being determined by the portfolio choice theory. Due to market frictions, the deviation between the offered and required risk premium evolves according to a mean-reverting process. Using 3-month ahead survey-based expectations of the US 3-month Treasury Bill rate, we employ Kalman filtering to estimate the market risk premium where the preference parameter of investors for alternative horizons is time-varying. We find that the market comprises both a group of agents with 3-month preferred horizon and a group of agents with 6-month preferred horizon with a weigh of two-thirds for the first group.
\end{abstract}

Keywords : interest rates, term structure, risk premium, survey data.

JEL Classification : C51, D84, E43, G11, G14

\footnotetext{
a EconomiX, Centre National de la Recherche Scientifique (CNRS) and University of Paris West Nanterre, France. E-mail address: georges.prat@parisnanterre.fr.

${ }^{\mathrm{b}}$ EconomiX, Centre National de la Recherche Scientifique (CNRS) and University of Paris West Nanterre, 200 Avenue de la République, 92001 Nanterre, France. Tel.:+33140977848. E-mail address: uctum@parisnanterre.fr (Corresponding author).
} 


\section{Introduction}

According to the theory of the term structure of interest rates, the spread between the long term rate and the short term rate equals the expected changes in the short rate plus a risk premium. Consequently, any empirical examination of this theory involves testing a joint hypothesis of the term structure relation and of hypotheses representing expected changes in the short rate and the risk premium, which both are not directly observable variables. In the literature, interest rate expectations are either assumed to be rational or determined by the historical values of observed rates, while the specification of the risk premium is either derived from an intertemporal equilibrium condition of the representative investor (portfolio choice model) or from an ad-hoc representation (constant or time-varying premium represented by an ARCH-in-mean model). Nevertheless, when the joint hypothesis mentioned above is rejected, it is not possible to conclude whether the rejection comes from the term structure relationship or from the hypotheses on expectations and risk premium. This is why, in order to solve these indeterminacies, some authors have used interest rate expectations provided by financial experts' surveys. Such survey data allow avoiding assumptions both on expectation formation and on the measurement of the ex-ante risk premium, but leaves unexplained the factors of the latter. Using survey data to measure short term interest rate expectations, the aim of this paper is to determine the risk premium in a two-horizon interest rate term structure model framework where the maturity of the riskless rate is at any time the one of the debt security whose duration equals the investor's desired horizon. This new approach allows us to determine a time-varying preference parameter of investors for alternative horizons, which thus relaxes the usual assumptions of the literature that the riskless rate is unchangingly the short period rate.

The risk premium related to maturity differences is a central concept in the decision making of various economic agents. Corporates and banks facing asset-liability maturity mismatch need to appraise how changes in interest rates of different maturities affect their insolvency probabilities. To this end, the asset portfolio managers of these firms strive to guess if the risk premia offered by the market compensate the risky arbitrage strategies between assets of different maturities. Besides, risk premia are viewed by financial institutions as an important determinant of long term interest rates, which represent both private sector's savings return and companies' capital cost. The countercyclical behaviour of risk premia is also of primary importance for central banks in establishing the effectiveness of the monetary policy (Bauer and Diez de los Rios, 2012). More particularly, the short side of 
the yield curve, which this paper will focus on, is a central concern not only of portfolio asset managers but also of treasury managers of banks and corporates. The latter institutions have indeed non-synchronized expected receipts and expenses and must handle the resulting financial gaps by selling or purchasing short term debt securities of different maturities. Uncertainty in gauging future receipts and expenses and the likelihood of choosing an inappropriate maturity lead agents to require a risk premium.

To appraise whether it is more appropriate to focus on an ex-ante or an ex-post representation of the risk premium, some investigation on the hypothesis of rationality of interest rate expectations is needed. Using data from various surveys and from various countries and periods, many authors have found evidence against the unbiasedness of expectations and thus rejected the rational expectation hypothesis (REH) (Friedman, 1979, 1980; Froot, 1989; Simon, 1989; Kim, 1997; MacDonald, 2000; Greer, 2003; Jongen and Veschoor, 2008; Prat and Uctum, 2010, 2017). ${ }^{1}$ Overall, the mainstream results show that, whatever the maturity of the debt, interest rate expectations based on survey data are not rational, which makes the ex-ante risk premium a more relevant concept than the ex-post premium based on the REH. We thus determine the ex-ante risk premium using a model of the term structure of interest rates with non-rational expectations.

Because survey data make that the expected change in the short term rate is directly measurable, the risk premium becomes observable, so that the term structure relationship can be tested using an appropriate modeling of the risk premium. Froot (1989) and MacDonald \& Macmillan (1994) found that the risk premium is significantly time-varying and concluded that the term structure model based on the pure expectations theory should be rejected. ${ }^{2}$ In this line, Prat and Uctum (2010) validated the term structure relationship in the 3-month maturity Eurofranc market by using a specific time-varying risk premium representation relying on the portfolio choice model.

\footnotetext{
${ }^{1}$ These results highlight the relevance of the question of how interest rate expectations are formed. On this topic, some studies have reported that each of the three traditional standard expectation rules - namely the extrapolative, the adaptive and the regressive rules - can partially explain interest rate expectations. Using survey data, Kane and Malkiel (1967) found support for extrapolative (bandwagon) and regressive expectations while Malkiel and Kane (1969) and Colletaz (1986) found evidence of adaptive expectations. More recently, Prat and Uctum (2018) showed that experts form their forecasts by combining four limited-information-based rules: the three traditional extrapolative, adaptive and regressive rules and a forward-market rule. The authors argue that such results are consistent with the economically rational expectations theory according to which information costs and agents' aversion to misestimating future interest rates determine the optimal amounts of information on which they base their expectations (Feige and Pearce, 1976).

${ }^{2}$ The countries analyzed in the former study are the U.S., Germany, Japan and Australia, while the latter study exploits data from U.K. and uses individual survey data. MacDonald (2000) provides an overview of the related literature.
} 
In the economic literature devoted to the term structure of interest rates, the riskless interest rate is generally given by the yield of a debt security with a one-period maturity, while the rate of the risky asset is the yield of a debt security with a multiple period-maturity (absence of default risk is supposed). It is thus implicitly assumed that the desired horizon is of one-period. This hypothesis is arbitrary, because the riskless rate is in principle given by the debt security whose duration is equal to the investor's horizon. Consequently, while the riskless rate is given by assets with one-period maturity for some investors whose horizon is of one period, assets with $n$-period maturity $(n>1)$ are considered as riskless assets for other investors whose horizon is of $n$ periods. The portfolio choice theory offers an appropriate framework to model the term structure of interest rates. Roll (1971) is among the pioneers of this approach using a CAPM framework. Shiller (1990) considers a consumption-based modelling where the risk-averse representative investor maximizes their expected utility of consumption. More recently, Artus (1990) and Prat and Uctum (2010) focus on the determination of the risk premium using a mean-variance representation and show that this modelling supports French data. According to the preferred-habitat theory (Modigliani and Sutch (1966)), an agent willing to invest over a given horizon is exposed to risk when they invest on a shorter or longer horizon. As a result, in contrast with the liquidity preference theory (Hicks, 1946) where the relationship between risk premium and maturity draws an increasing curve, this relationship in preferred-habitat has a U-shape of which the minimum at the zero risk premium reflects the preferred horizon. Note that, unlike the theory of segmented markets (Culbertson, 1957), any agent can invest in maturities that differ from their preferred habitat if the market offers them an attractive premium. Nevertheless, in its strict formulation, the preferred-habitat theory leaves undetermined the habitat premium, i.e., the risk premium required by the risk averse lender to depart from their preferred-habitat. In our paper we aim to fill this gap and seek to model the determination of the required risk premium. As an alternative approach of the extant literature on the term structure of interest rates, affine models, introduced by Duffie and Kan (1996), are used to explain the dynamics of the term structure under various sources of uncertainty, named factors. In the basic single-factor case, where the factor is most generally identified with the instantaneous interest rate, these models assume that the zero-coupon bond price is an affine function of the short term interest rate whose instantaneous dynamics is described by a first-order stochastic differential equation. While the standard affine models assume the price of risk as constant, Dai and Singleton (2002) introduce state-dependent price of risk. Using an extended affine model, the authors derive time varying risk premia of a form consistent with the Fama and Bliss (1987) results 
and find that these premia help addressing the puzzle in testing the expectations hypothesis of the term structure of interest rates for long maturity bonds. ${ }^{3}$ Ang et al. (2008) analyze the term structure of real interest rates and inflation risk premia using an affine regime-switching model. Ichiue and Ueno (2013) and Christensen and Rudebusch (2016) compare the performance of a standard affine dynamic term structure model which ignores the ZLB to that of a shadow-rate dynamic term structure model which accounts for the ZLB. ${ }^{4}$ The authors show that, because of this drawback, the affine model underperforms the shadow rate model and leads to underestimate the risk premium during the ZLB period, while both approaches allow comparable results out of this period.

Combining the preferred-habitat approach with the affine model framework, Vayanos and Vila (2009) propose a theoretical model of the term structure of interest rates based on the interaction between two types of agents: preferred-habitat investors with strict preferences for specific maturities and risk-averse arbitrageurs who integrate all maturity markets and ensure at any time the absence of arbitrage opportunity. Among other results from their two-factor model, the authors find that bond risk premia are positive (negative) when the short rate is low (high) or when bond prices are low (high) because investors' demand is low (high). Nonetheless, the model is based on the hypothesis that investors' habitats are totally and unchangingly segmented, and this is a strong assumption in regards of real financial markets where most often investors act at the same time as arbitrageurs. ${ }^{5}$ It seems to us more realistic to distinguish such investors by their time-dependent preferred habitats within an unsegmented market, where at each point in time they take risky or riskless positions according to their expected gains from the two strategies.

Whether they are proposed within portfolio choice, preferred habitat or affine models, numerous interest rate term structure relationships make in common the assumption that a

\footnotetext{
${ }^{3}$ This puzzle states that for different maturities, the linear regression of the change in yields onto the spread between long and short rates leads to a negative slope while the slope implied by the expectations hypothesis is unity.

${ }^{4}$ The shadow rate is defined as the rate that would prevail in the absence of lower bound constraint (see Black, 1995). In the shadow rate model the short rate is equal to the shadow rate when this rate is positive and zero otherwise. Conversely, in the standard affine model, the short rate follows a Gaussian process and the model allows then negative interest rates for all maturities.

5 Investors act as arbitrageurs because they are assumed to behave as "active portfolio managers", a concept introduced by Grinold (1989) and Grinold and Kahn (2000). In constructing a portfolio, active ("long-short") portfolio management consists in attempting to beat the market by mobilizing at any time in-depth analysis and research along with increased expertise skills. By comparison, passive ("long-only") management aims to generate the returns of a benchmark portfolio without seeking to outperform it. Most of the empirical studies (e.g., Clarke et al., 2002) have shown that the long-short strategy beats the long-only one in terms of portfolio efficiency. Using a new multi-factor econometric approach, Ding and Martin (2017) found support to the relevance of active portfolio management.
} 
lender can invest in an asset whose maturity differs from the preferred horizon provided that the market offers sufficient incentive for this alternative. A major drawback of these term structure relationships is that the preferred horizon is systematically assumed to be determined by the maturity of the short rate and, consequently, that the short rate asset is always considered as the riskless investment. These approaches do not allow agents to consider longer term zero-coupon and zero-default debt securities as riskless investments even though maturities correspond to desired horizons. Yet, longer term investors may have advantage in taking risky positions by contracting a sequence of short-term debts. The main novelty of this paper consists precisely in proposing a model where the riskless rate for any investor is the one of the claim whose maturity coincides with their horizon of investment. This relaxes the usual assumption in the literature that the 1-period rate is the riskless rate at any time and for all agents. In our model, agents decide whether or not they stand on their desired horizon to realize a riskless investment depending on the risk premium offered by the market. Using three-month horizon expectations of the US three-month maturity Treasury Bills rate provided by Consensus Economics surveys (London) over the period November 1989 - May 2015, we estimate a hybrid interest rate term structure model based on the portfolio choice theory where a representative investor compares the risk premium offered by the market to the value they require for the 3 and 6-month horizons. We show that the market premium gradually adjusts towards the required premium due to the existence of market frictions. The estimated timevarying weights assigned by the market to the alternative preferred horizons imply that interest rates of both maturities are regarded by different groups of investors as riskless rates, the alternative rates being then considered by the groups as risky. To our knowledge, such a hybrid model is novel in the literature and contributes to better understanding the term structure of interest rates.

In Section 2 we describe the theoretical foundations of the proposed model. Section 3 outlines the data used and provides some stylized facts. In Section 4 we present our empirical mean-reverting adjustment process towards risk premium equilibrium and discuss the Kalman filter estimation results of the associated state space model. Section 5 concludes.

\section{Theoretical issues}

\subsection{Time horizons of investors, debt security maturities and ex-ante market risk premia}


A zero-coupon debt security market without default risk is riskless if its maturity is equal to the desired investment horizon. Consider two zero-coupon and zero default risk assets with $\tau$ and $n \tau$ month maturities, which offer the yields ${ }_{\tau} r_{t}$ and ${ }_{n \tau} r_{t}$, respectively. We will call ${ }_{\tau} r_{t}$ the "short term rate" and ${ }_{n \tau} r_{t}$ the "long term rate", where $n>1$ is the ratio between the maturities of the long and the short term debt securities. For a risk-averse investor $i$ willing to realize a $\tau$-month ( $n \tau$-month) period investment the riskless interest rate is ${ }_{\tau} r_{t}\left({ }_{n \tau} r_{t}\right)$.

At time $t$, this investor is faced with two choices: (a) buy the $\tau$-month debt security that ensures the yield ${ }_{\tau} r_{t}$ between $t$ and $t+\tau$, or (b) buy the $n \tau$-month debt security in the prospect of selling it at $t+\tau$ given that its return ${ }_{n \tau} h_{t, t+\tau}$ between $t$ and $t+\tau$ is random since its future price at $t+\tau$ is unknown at $t$. The investor will choose (b) only if their expected return in holding the long-maturity asset over $\tau$ months exceeds ${ }_{\tau} r_{t}$ by an amount deemed sufficient to compensate the risk incurred. When the debt securities are "zero coupon" bonds with continuous and compound interest ${ }^{6}$, the $\tau$-month ahead expected return of the longmaturity debt security is written, on a monthly basis, as ${ }^{7}$ :

$$
\frac{1}{\tau} E_{i t}\left({ }_{n \tau} h_{t, t+\tau}\right)=n_{n \tau} r_{t}-(n-1) E_{i t}\left({ }_{(n-1) \tau} r_{t+\tau}\right)
$$

where $E_{i t}\left({ }_{(n-1) \tau} r_{t+\tau}\right)$ stands for the $\tau$-month horizon expected return of the debt security that has a residual maturity of $(n-1) \tau$ months. For an investment horizon of $\tau$ months, the risk $\operatorname{premium}_{\tau} \phi_{i t}^{(n)}$ is defined as the difference between the $\tau$ month-ahead expected return of the $n \tau$-maturity debt security, $E_{i t}\left({ }_{n \tau} h_{t, t+\tau}\right) / \tau$, and the interest rate of the $\tau$-month maturity

\footnotetext{
${ }^{6}$ Recall that a property of a zero-coupon instrument is that residual maturity equals duration. This is an interesting feature in that what matters in risk management strategies is duration and not maturity. For example, an investor with a given investment horizon takes no risk if their portfolio duration is equal to their horizon.

${ }^{7}$ The price of a zero coupon debt security with maturity $n \tau$ months equals the discounted value of future receipts, so that ${ }_{n \tau} C_{t}=F / e^{n \tau}{ }_{n} r_{t}$, where $F$ is the nominal value, known at time $t$, which will be paid at maturity (interests plus repayment), and ${ }_{n \tau} r_{t}$ the interest rate (expressed in decimal-monthly basis) of the $n \tau$ months debt security. Accordingly, and noting that the $n \tau$-month security at time $t$ becomes a $(n-1) \tau$-month security at time $t+\tau$, the expected return of the long term security between $t$ and $t+\tau$ is written as $E_{i t}\left({ }_{n \tau} h_{t, t+\tau}\right)=E_{i t}\left[\log \left({ }_{(n-1) \tau} C_{t+\tau} /{ }_{n \tau} C_{t}\right)\right]$, where $E_{i t}$ is the conditional expectation for investor $i$. Reporting the former equation into the latter and dividing by $\tau$ leads to Eq.(1).
} 
debt security, ${ }_{\tau} r_{t}$. Using Eq. (1), this $\tau$-month risk premium offered by the market to agent $i$ writes

$$
{ }_{\tau} \phi_{i t}^{(n)}=n_{n \tau} r_{t}-(n-1) E_{i t}\left({ }_{(n-1) \tau} r_{t+\tau}\right)-{ }_{\tau} r_{t}
$$

Assume now that the investor $i$ favors the long horizon instead of the short one and is willing to invest over $n \tau$-months. The riskless choice (a) consists in purchasing the $n \tau$-month maturity debt security with a risk-free return ${ }_{n \tau} r_{t}$, allowing for the total return $n_{n \tau} r_{t}$. The risky choice (b) consists in purchasing the $\tau$-month maturity debt in view of repeating the purchase in $\tau$ months, $2 \tau$ months, ... (n-1) $\tau$ months given that prices of the $\tau$-month asset at $t+\tau, t+2 \tau, \ldots, t+(n-1) \tau$ are unknown at $t$. The $n \tau$-month ahead expected total return for the speculative behavior (b) is then ${ }_{\tau} r_{t}+E_{i t} \sum_{k=1}^{n-1}{ }_{\tau} r_{t+k \tau}$, which must be compared to the secure choice (a). Accordingly, the $n \tau$-month ex-ante risk premium offered by the market to agent $i$ can be written as:

$$
{ }_{n \tau} \phi_{i t}^{(n)}={ }_{\tau} r_{t}+E_{i t} \sum_{k=1}^{n-1}{ }_{\tau} r_{t+k \tau}-n_{n \tau} r_{t}
$$

Due to limitations implied by the availability of survey data on interest rate expectations, we consider the case $n=2$ from now on. We thus do no longer specify it at the superscript of the risk premium for the sake of notational simplicity. Thus, the alternative exante premia (2) and (3) offered by the market to agent $i$ according to whether their desired horizon is $\tau$ or $2 \tau$ reduce to ${ }_{\tau} \phi_{i t}=2{ }_{2 \tau} r_{t}-E_{i t}\left({ }_{\tau} r_{t+\tau}\right)-{ }_{\tau} r_{t} \quad$ and ${ }_{2 \tau} \phi_{i t}={ }_{\tau} r_{t}+E_{i t}\left({ }_{\tau} r_{t+\tau}\right)-22 \tau r_{t}$, respectively. Note that these premia ${ }_{\tau} \phi_{i t}$ and ${ }_{2 \tau} \phi_{i t}$ can be assessed by the investor $i$ since their expected $\tau$-month rate is obviously known to them and the two market rates are observable.

At any time, agents adjust their preferred horizons to their liquidity constraints, i.e., to the restrictions they bear on the amount of cash they can make available, preventing them from optimizing their saving and spending over time. These liquidity constraints are due to the time lags between their revenues and their expenses, which themselves depend on the structure of their assets and liabilities. A good example is the transaction demand for cash model proposed by Allais (1947, pp. 238-40) and popularized by Baumol (1952) and Tobin (1956), which describes a rational agent's behavior with regard to such a time lag. This model 
determines at any time an agent's optimal stock of money, given that their revenues and expenses are realized at different dates and that they allocate their available funds on short term maturity investments at a given interest rate net of transaction costs. Without such liquidity constraints, we can assume that investors would simulate different optimal portfolios with different horizons and select the horizon allowing for the highest expected utility (i.e., the highest expected return for a given risk or the lowest risk for a given expected return). In this case, the highest actualized expected utility determines both the preferred horizon and the corresponding risk premium required for investing in assets with a maturity different from this horizon. Thus, with or without liquidity constraints, an agent cannot have more than one single preferred horizon. Once the preferred horizon is set, the issue is how agents make their decisions given the premium offered by the market. In this context, decisions to sell or to purchase financial assets result from the confrontation between the premium offered by the market and the premium required by investor $i$. The latter premium is derived from the maximization of their real wealth expected utility subject to their budget constraint. The optimal portfolio is then comprised of a proportion of riskless asset whose residual maturity equals the desired horizon at the one hand, and a proportion of risky asset whose maturity differs from the desired horizon, at the other hand. It should be emphasized that the choice of the preferred horizon may change between $t$ and $t+1$, notably due to liquidity constraints, and an attempt to model this time-varying feature of the horizon preference is a cornerstone of our paper.

Of course, the whole panel of investors consists in a multitude of agents $i$. We now describe the ex-ante market risk premium using the representative agent concept. If the aggregate $\tau$ and $2 \tau$-month debt securities market is comprised of $p$ investors, the representative agent's expectation is given by the market belief that is $E_{M t}\left({ }_{\tau} r_{t+\tau}\right)=\frac{1}{p} \sum_{i=1}^{p} E_{i t}\left({ }_{\tau} r_{t+\tau}\right)$. It hence follows from the aggregation of Eqs.(2) and (3) above that the ex-ante risk premia offered by the market to the representative agent for the $\tau$ and $2 \tau$-month horizons can be written as

$$
{ }_{\tau} \phi_{M, t}=2{ }_{2 \tau} r_{t}-E_{M, t}\left({ }_{\tau} r_{t+\tau}\right)-{ }_{\tau} r_{t}
$$

and

$$
{ }_{2 \tau} \phi_{M, t}={ }_{\tau} r_{t}+E_{M, t}\left({ }_{\tau} r_{t+\tau}\right)-2{ }_{2 \tau} r_{t}
$$


It can be straightforwardly seen that each premium can take any sign, that they both have the same absolute value but are of opposite signs, that is ${ }_{\tau} \phi_{M t}=-{ }_{2 \tau} \phi_{M t}{ }^{8}$ As will be shown below, this particularity has the advantage of simplifying our modeling.

To describe the decision making mechanisms for both horizons, it is now necessary to consider the premia ${ }_{\tau} \phi_{M t}^{*}$ and ${ }_{2 \tau} \phi_{M t}^{*}$ required by the $\tau$ and $2 \tau$-month horizon investors to describe supply and demand flows of securities in terms of portfolio adjustments. For each horizon, the required premia corresponds to the optimal portfolio composed of $\tau$ and $2 \tau$ month maturities debt securities (see section 2.2). For example, consider at time $t$ that the representative investor is concerned by the $\tau$ month horizon. If their expectation $E_{M t}\left({ }_{\tau} r_{t+\tau}\right)$ and the interest rates ${ }_{\tau} r_{t}$ and $2 \tau{ }_{2}$ are such that the condition ${ }_{\tau} \phi_{M t} \geq{ }_{\tau} \phi_{M t}^{*}$ holds ${ }^{9}$ (i.e. the market offers not less than what they require), then they will have incentive to sell $\tau$ months riskless assets and to purchase $2 \tau$-month risky assets with the intention of reselling the latter $\tau$ months later; as a result, ${ }_{\tau} r_{t}$ should rise and ${ }_{2 \tau} r_{t}$ should decline, implying a decrease in ${ }_{\tau} \phi_{M t}$. If now the condition ${ }_{\tau} \phi_{M t}<{ }_{\tau} \phi_{M t}^{*}$ holds, the investor will sell the $2 \tau$-month risky asset and purchase the $\tau$-month debt offering a riskless return. In this case, ${ }_{\tau} r_{t}$ should decrease and ${ }_{2 \tau} r_{t}$ should rise, implying an increase in ${ }_{\tau} \phi_{M t}$. Similar adjustments occur when ${ }_{2 \tau} \phi_{M t} \neq{ }_{2 \tau} \phi_{M t}^{*}$. Consequently, whatever the horizon, any deviation between observed and required premia triggers adjustments in interest rates which help to restore equilibrium. When the market is at equilibrium (no arbitrage opportunity), $\tau$ - and $2 \tau$-month investors hold a total wealth consisting of optimal shares of $\tau$-month and $2 \tau$-month assets.

\subsection{The required risk premia according to investment horizons}

In section 2.1. we described the decision making process of a representative investor who has two preferred habitats of $\tau$ and $2 \tau$ month horizons and who therefore only holds assets of $\tau$ and $2 \tau$ maturities since these assets offer them riskless rates for these horizons. This accounts to assume that the market comprises one group of $\tau$-month horizon investors and another group of $2 \tau$ month horizon investors, the size of each group being time varying

\footnotetext{
${ }^{8}$ Recall that such symmetry holds only when the ratio $n$ between the long and the short-term maturities equals 2 in $\mathrm{Eq}(2)$ and $\operatorname{Eq}(3)$.

${ }^{9}$ Since both observed and required values may take positive or negative values (for the case of required values see section 2.2), the arbitrages described below apply whatever the sign of the premia.
} 
as agents can switch from one group to the other depending on their strategy at any time. A complete model would clearly include simultaneously all the possible horizons desired by all agents and all the maturities existing in the market, so that we would determine as many optimal portfolios (each one including the whole set of maturities) and required risk premia as there are desired horizons. Such a model would be intractable because of the very high number of required premia to be derived (one per desired horizon). In addition, such a diversification in horizons would increase the need for survey-based data on interest rate expectations for these horizons and would meet a problem of data availability. Our representative agent is supposed to make separately for each horizon a "mental accounting"10 to assess the value of the equilibrium risk premium corresponding to the optimal portfolio composed by $\tau$ - and $2 \tau$-month debt securities. Because our investor is a representative agent, regardless their wish to invest at $\tau$-and $2 \tau$-months the two mental accounts involve at time $t$ the same total wealth, the same aggregate $\tau$ - month rate expectation, the same expected volatility and the same preference parameters.

The $\tau$-month horizon investment strategy

The representative investor optimizes the shares of short and long assets by maximizing the expected utility of their real wealth at time $t$ for the next period conditional on a given set of information. The investor is risk averse and has a CARA utility function $U\left(W_{t} / P_{t}\right)=1-e^{-\rho W_{t} / P_{t}}\left(U^{\prime}>0\right.$ and $\left.U^{\prime \prime}<0\right)$, where $W_{t}$ is the nominal wealth, $P_{t}$ is the general price level and $\rho>0$ the constant absolute risk aversion coefficient. Assuming that $W_{t} / P_{t}$ is normally distributed, the program of the investor for the time-horizon $\tau$ can be written in the mean-variance form as follows:

$$
\operatorname{Max}_{t}\left[U\left(\frac{P_{t}}{P_{t+\tau}} W_{t+\tau}\right)\right]=\operatorname{Max}_{t}\left[\left(\frac{P_{t}}{P_{t+\tau}} W_{t+\tau}\right)-\frac{\rho}{2} \operatorname{Var}_{t}\left(\frac{P_{t}}{P_{t+\tau}} W_{t+\tau}\right)\right]
$$

subject to the budget constraint

$$
W_{t}={ }_{\tau} N_{t} /\left(1+{ }_{\tau} r_{t}\right)+{ }_{2 \tau} N_{t} /\left(1+{ }_{2 \tau} r_{t}\right)^{2}
$$

\footnotetext{
${ }^{10}$ Thaler (1999) defines mental accounting as "cognitive operations used by individuals and households to organize, evaluate, and keep track of financial activities". To overcome complex economic decision tasks individuals make their decision in a piecemeal fashion, creating different categories for spending, each category corresponding to a separate mental account. Mental accounting is a way used by bounded rational agents to simplify economic decision making.
} 
where $E_{t}$ and $\operatorname{Var}_{t}$ are conditional expectation and variance operators of the future real wealth, ${ }_{\tau} N_{t}$ is the amount of the face value of the $\tau$-month maturity debt and ${ }_{2 \tau} N_{t}$ the amount of the face value of the $2 \tau$-month maturity debt.

At $t+\tau$, investor's wealth from the same portfolio composed at $t$ is given by

$$
W_{t+\tau}={ }_{\tau} N_{t}+{ }_{2 \tau} N_{t} /\left(1+{ }_{\tau} r_{t+\tau}\right)
$$

Solving for $W_{t+\tau}$ by eliminating ${ }_{\tau} N_{t}$ between Eqs.(7) and (8) leads to approximate the argument of the expectation and the variance operators in Eq.(6) as follows ${ }^{11}$ :

$$
\frac{P_{t}}{P_{t+\tau}} W_{t+\tau}=\frac{P_{t}}{P_{t+\tau}} W_{\tau}\left(1+{ }_{\tau} r_{t}\right)+{ }_{2 \tau} N_{t}\left(2{ }_{2 \tau} r_{t}-{ }_{\tau} r_{t}-{ }_{\tau} r_{t+\tau}\right)
$$

Reporting Eq.(9) into Eq.(6) and maximizing for ${ }_{2 \tau} N_{t}$ leads to the following required value of the market risk premium:

$$
{ }_{\tau} \phi_{M, t}^{*}=\rho W_{t}\left(\omega_{t} V_{t}+\operatorname{Cov}_{t}\right)
$$

where $V_{t}=V_{t}\left({ }_{\tau} r_{t+\tau}\right)$ represents the expected variance of the short rate, $\operatorname{Cov}_{t}=\operatorname{cov}\left({ }_{\tau} r_{t+\tau}, \pi_{t+\tau}\right)$ the expected covariance between the short rate and upcoming inflation (defined as $\pi_{t+\tau}=\log \left(P_{t+\tau} / P_{t}\right)$ ) and $\omega_{t}$ the share of the $2 \tau$-month asset in the portfolio, such that:

$$
\omega_{t}=\frac{{ }_{2 \tau} N_{t} /\left(1+{ }_{2 \tau} r_{t}\right)^{2}}{W_{t}}
$$

The $2 \tau$ - month horizon investment strategy

The program of the representative agent is now:

$$
\operatorname{Max}_{t}\left[U\left(\frac{P_{t}}{P_{t+2 \tau}} W_{t+2 \tau}\right)\right]=\operatorname{Max}\left[E_{t}\left(\frac{P_{t}}{P_{t+2 \tau}} W_{t+2 \tau}\right)-\frac{\rho}{2} \operatorname{Var}_{t}\left(\frac{P_{t}}{P_{t+2 \tau}} W_{t+2 \tau}\right)\right]
$$

\footnotetext{
${ }^{11}$ To obtain expression $(9)$ the following approximation has been used: $\left(P_{t} / P_{t+\tau}\right)\left(2{ }_{2 \tau} r_{t}-{ }_{\tau} r_{t}-{ }_{\tau} r_{t+\tau}\right) /\left[\left(1+{ }_{\tau} r_{t+\tau}\right)\left(1+{ }_{2 \tau} r_{t}\right)^{2}\right] \approx 22 \tau r_{t}-{ }_{\tau} r_{t}-{ }_{\tau} r_{t+\tau}$. For $\tau=3$, the empirical correlation between the two sides of this proxy is found to be 0.998 , which makes the approximation admissible.
} 
subject to the same budget constraint (7) as above. The wealth at time $t+2 \tau$ is now defined as $W_{t+2 \tau}={ }_{\tau} N_{t}\left(1+{ }_{\tau} r_{t+\tau}\right)+{ }_{2 \tau} N_{t}$. A similar derivation as above leads to the following required value of the market risk premium:

$$
{ }_{2 \tau} \phi_{M, t}^{*}=\rho W_{t}\left[\left(1-\omega_{t}\right) V_{t}-\operatorname{Cov}_{t}\right]
$$

where we assumed that $\operatorname{Cov}_{t}\left({ }_{\tau} r_{t+\tau}, \pi_{t+2 \tau}\right) \approx \operatorname{Cov}_{t}\left({ }_{\tau} r_{t+\tau}, \pi_{t+\tau}\right)=\operatorname{Cov}_{t} \cdot{ }^{12}$ Eq. (13) provides the required value to which the observed $2 \tau$-month premium given by Eq.(5) converges. It can be seen from Eqs. (10) and (13) that the values of the $\tau$ and $2 \tau$-month required premia are not opposed to each other, contrary to the observed premia (4) and (5). This is due to the fact that planning, at time $t$, to sell a $2 \tau$-month Bill at time $t+\tau$ (i.e., implementing a $\tau$ month horizon risky strategy) does not imply a symmetric risk exposure than planning, at time $t$, to buy a $\tau$-month Bill at time $t+\tau$ (i.e., following a $2 \tau$ - month horizon risky strategy). Indeed, redeeming the long term asset before maturity and scheduling the reinvestment of the short term asset involve uncertainty in the next $\tau$-month return and the one after which imply different management approaches over subsequent periods.

We can infer from Eq.(10) that if the expected covariance between interest rate and inflation is positive, then the required premium ${ }_{\tau} \phi_{M, t}^{*}$ is positive. Conversely, if this covariance is negative and if the expected variance of interest rate is smaller than or equal to the absolute value of the covariance, then the premium is negative. For a $\tau$-month period investment, a negative required risk premium has the economic sense that the assessment of inflation risk adds up to interest rate risk, or in other words that the actual interest rate ${ }_{\tau} r_{t}$ is perceived as not compensating future inflation, which affects negatively the expected real wealth. In this case, the agent willing to invest for a $\tau$ - month period might accept to pay a premium to purchase the $2 \tau$-month maturity debt security in view of selling it $\tau$ months later. This strategy would allow the agent to reduce their loss, and even to expect profit if the price of the 6-month asset were to increase significantly to offset upcoming inflation. In the same manner, Eq.(13) suggests that according to the values of the variance and of the covariance, the required $2 \tau$-month premium can be of any sign.

\footnotetext{
${ }^{12}$ It seems indeed unlikely that agents might make a clear distinction between the two expected covariances, especially since the horizon of $\pi_{t+\tau}$ overlaps by $50 \%$ the one of $\pi_{t+2 \tau}$.
} 


\subsection{The market equilibrium condition}

At the aggregate supply side, it follows from the symmetry between Eqs.(4) and (5) that, at any time, representing one of the premia amounts to representing the opposite of the other one by using the same set of information. We can then express the ex-ante market premium using indistinguishably the same measure for the two horizons, provided that this measure can take any sign. We arbitrarily choose to specify the ex-ante market premium using the $\tau$-month horizon measure, that we call the "two-horizon ex-ante premium offered by the market" and that we define as:

$$
\phi_{M t}=22_{2 \tau} r_{t}-E_{M t}\left({ }_{\tau} r_{t+\tau}\right)-{ }_{\tau} r_{t}
$$

According to Eq.(14), a positive (negative) value of $\phi_{M, t}$ means that the market premium is positive (negative) at the $\tau$-month horizon but negative (positive) at the $2 \tau$ month one.

At the aggregate demand side, the representative agent who reflects all investors in the market is concerned at any time by both horizons $\tau$ and $2 \tau$. Accordingly, the two-horizon required market premium $\phi_{M, t}^{*}$ can be represented by a weighted average of ${ }_{\tau} \phi_{M, t}^{*}$ and ${ }_{2 \tau} \phi_{M, t}^{*}:$

$$
\phi_{M, t}^{*}=\lambda_{t \tau} \phi_{M, t}^{*}+\left(1-\lambda_{t}\right)_{2 \tau} \phi_{M, t}^{*} \quad 0 \leq \lambda_{t} \leq 1
$$

where $\lambda_{t}$ stands for the weight granted by the representative agent to the $\tau$-month horizon in their required premium, thus measuring the agent's degree of preference for this horizon visà-vis risky strategies. Reporting Eqs (7) and (11) into Eqs (10) and (13) and these two into Eq (15), the reduced expression of the market required premium writes:

$$
\begin{aligned}
\phi_{M, t}^{*}=\rho\left\{V_{t}[\right. & \left.\left(1-\lambda_{t}\right){ }_{\tau} N_{0} /\left(1+{ }_{\tau} r_{t}\right)+\lambda{ }_{t}{ }_{2 \tau} N_{0} /\left(1+{ }_{2 \tau} r_{t}\right)^{2}\right] \\
& +\left(2 \lambda_{t}-1\right) \operatorname{Cov}_{t}\left({ }_{\tau} N_{0} /\left(1+{ }_{\tau} r_{t}\right)+{ }_{2 \tau} N_{0} /\left(1+{ }_{2 \tau} r_{t}\right)^{2}\right\}
\end{aligned}
$$

where $\lambda_{t}, V_{t}$ and $\operatorname{Cov}_{t}$ will be given empirical specifications in section 4.1. Note, from Eq.(15), that at any time $t$, the sign of the premium required by the market depends both on the signs of ${ }_{\tau} \phi_{M, t}^{*}$ and of ${ }_{2 \tau} \phi_{M, t}^{*}$ and on the value of $\lambda_{t}$. In the literature, it is generally 
assumed that $\lambda_{t}=1 \forall t$, that is $\phi_{M, t}^{*}={ }_{\tau} \phi_{M, t}^{*}$, which means that ${ }_{\tau} r_{t}$ and ${ }_{2 \tau} r_{t}$ are at any time the risk-free and the risky rates, respectively. This implies that the horizon of the market is assumed to be unchangingly $\tau$ months. While in some cases this restrictive assumption may prove compatible with the term structure model, the restrictive hypothesis that $\lambda_{t}$ equals 1 at each point in time was strongly rejected with our data. This is notably due to the fact that the required risk premium ${ }_{\tau} \phi_{M, t}^{*}$ is not sufficient on its own to account for the alternating signs of the observed market risk premium $\phi_{M, t}$ (see figure 1). This shortcoming of the literature can be addressed by using our two-horizon required market premium to characterize the demand-side of the debt market. Accordingly, the equilibrium condition $\phi_{M, t}=\phi_{M, t}^{*}$ leads to equalize the right hand sides of Eqs.(14) and (15), hence

$$
2{ }_{2 \tau} r_{t}-E_{M t}\left({ }_{\tau} r_{t+\tau}\right)-{ }_{\tau} r_{t}=\lambda_{t \tau} \phi_{M, t}^{*}+\left(1-\lambda_{t}\right){ }_{2 \tau} \phi_{M, t}^{*}
$$

Regarding Eq.(17), it is useful to discuss the limit cases when $\lambda_{t}$ reaches the values 0 and 1 . If $\lambda_{t}=1$, the market offers to the representative agent a premium that directly identifies with the $\tau$-month premium (4); at equilibrium, Eq.(17) writes $2{ }_{2 \tau} r_{t}-E_{M, t}\left({ }_{\tau} r_{t+\tau}\right)-{ }_{\tau} r_{t}={ }_{\tau} \phi_{M, t}^{*}$. If now $\lambda_{t}=0$, then the market offers to the representative agent a premium which is given by the $2 \tau$-month premium (5); at equilibrium, this state of the nature is given by ${ }_{\tau} r_{t}+E_{M, t}\left({ }_{\tau} r_{t+\tau}\right)-2{ }_{2 \tau} r_{t}={ }_{2 \tau} \phi_{M, t}^{*}$. However, given the symmetry between the observed market premia, the equilibrium condition (17) is still consistent with this limit case in the sense that any value of the required $2 \tau$-month premium generates the opposite value in the dependent variable $2{ }_{2 \tau} r_{t}-E_{M t}\left({ }_{\tau} r_{t+\tau}\right)-{ }_{\tau} r_{t}$. For example, a $\tau$-month required premium of $1 \%$ implies an observed value of $1 \%$ when $\lambda_{t}=1$, while a $2 \tau$-month required premium of $1 \%$ produces an observed value of $-1 \%$ when $\lambda_{t}=0$. The appropriateness of the two-horizon market premium in representing these extreme cases can be generalized to any value of the weighting coefficient $\lambda_{t}$.

\subsection{The adjustment of the observed market premium to its equilibrium value}


When the deviation $z_{t}=\phi_{M t}-\phi_{M t}^{*}$ between observed and required market premia is zero, there are no arbitrage opportunities, but when $z_{t}>0\left(z_{t}<0\right)$, agents can - to the extent of limits to arbitrage - improve their utility by selling or buying Bills (see section 2.1 above). A non-zero deviation can result from market frictions due to liquidity constraints, to regulation of the short term rate by the Federal Reserve, to search costs (especially asset selection costs in portfolio optimization) and to information costs related to the determination of the required value. As shown by Anderson (1997) for the US Treasury bill rate, transaction costs can also cause deviations between price and required value. Moreover, by influencing the market volatility, noise traders' behaviour may lead to mispricing the equilibrium value of an asset; this generates uncertainty about the true equilibrium value and then contributes to make arbitrage risky (Shleifer and Summers (1990)). Consequently, both transaction costs and risky arbitrage can set limits to arbitrage at some point and imply that the deviations between the market offered and required risk premia follow a mean-reverting adjustment process (Jawadi and Prat (2012) $)^{13}$ Accordingly, assuming the adjustment process is linear ${ }^{14}$, the dynamics of the spread between observed $\phi_{M, t}$ and required premia $\phi_{M, t}^{*}$ is represented by the following error correcting model (ECM) which describes the adjustment of deviation $z_{t}$ towards its $\operatorname{target} \phi_{M, t}-\phi_{M, t}^{*}=0$ :

$$
\Delta z_{t}=-\kappa z_{t-1}+\sum_{q=1}^{m} a_{q} \Delta z_{t-q}+\zeta_{t} \quad 0 \leq \kappa \leq 1
$$

\section{Data and stylized facts}

\subsection{Observed and expected US Treasury Bills rates}

Our study is concerned with the US Treasury Bills market. T-Bills are the most marketable debt and are a way for the U.S. government to raise money from the public. They are short-term securities whose maturities range from a few days to a maximum of 52-weeks,

\footnotetext{
${ }^{13}$ For a group of investors, the absolute deviation may exceed their arbitrage costs (defined as the sum of transaction costs plus a risky arbitrage premium), so that they will trigger a mean-reverting mechanism towards their equilibrium values. For other investors, arbitrage costs may be larger than absolute deviation, in which case there is no mean-reversion. The larger the proportion of mean-reverting agents, the higher the strength of the market adjustment, implying nonlinearity in the adjustment process if the proportion of the two groups is timevarying. In this paper, the focus is put on testing the nonlinearity underlying the relative preference of the market for the short or long horizons of investment, while the proportions of the two groups mentioned above are supposed to be stable throughout our sample period.

${ }^{14}$ The validity of this assumption will be empirically checked in section 4.2.
} 
but common maturities are 1-, 3-, 6- and 12-months. T-Bills rates have many advantages. First, a T-Bill is a simple zero-coupon debt: it is purchased for a price that is less than its face value, the government paying the holder the full par value when it matures; interest paid is thus the difference between the purchase price of the Bill and what the investor gets at maturity. This implies that the duration equals the residual maturity; this is an important feature, since a riskless claim is a claim whose duration equals the horizon of the investment. Second, T-Bills are affected by no default risk because they are fully guaranteed by the U.S. government and the Department of the Treasury. Third, income from T-Bills is generally exempt from state and local taxes (although they are subject to federal income taxes). Fourth, investors can keep funds in these debt securities if they believe that they may have some need of cash within the next period. T-Bills are also very easy to buy and sell because they require a minimum investment of $\$ 100$ and do not have any call provision. This implies that, in times of declining interest rates, when corporate bonds are often being called in by their issuers, TBill investors have peace of mind knowing exactly how long they can hold their securities. The fact that T-Bills are highly liquid enables investors to easily manage their liquidity constraints. Note that within the T-Bills market, maturity-arbitrage and thus risk premia are not in principle distorted by behaviour such as "flight to quality" or "flight to liquidity" since T-Bills have no default risk and have the same degree of liquidity.

Our data covers the period November 1989 - May 2015. At the beginning of each month, Consensus Economics (CE, London) asks about 200 economists, financial market operators and executives in various institutions (commercial and investment banks, forecasting agencies and industrial corporations) in over 30 countries to forecast future values of principal macroeconomic variables - such as GDP growth, CPI growth, interest rates, exchange rates, current account - for the three and the twelve month horizons. In particular, the CE newsletter publishes every month the "consensus" corresponding to the arithmetic average of individual expected values of the 3-month Treasury Bill rate. Consequently, from now on, we set the short rate maturity to $\tau=3$ months (given that $\mathrm{n}=2$, the long rate maturity is then 6 months). According to Eqs (4) and (5), the only expected variable we need is the 3month ahead expected 3-month maturity interest rate.

About 30 financial institutions are asked to predict the 3-month expected value of the short rate, of which the consensus value is denoted as $E_{t}\left({ }_{3} r_{t+3}\right)$. These institutions are, by their own activity, directly concerned by forecasting US interest rates and include essentially major American banks (Bank of America, Goldman Sachs, Barclays, Wells Fargo, JP Morgan, 
Northern Trust...), investment advisory firms (First Trust Advisor, Wells Capital Management...), research organizations or academic institutions (The Conference Board, Moody's Analytics, RDQ Economics, Georgia State University, University of Michigan, University of Maryland...), and industrial companies (General Motors, Eaton Corporation...). The experts only answer when they think they have a good knowledge about the variable of interest, and this allows assuming that those who respond are informed agents. ${ }^{15}$ Since the individual answers are confidential (only the consensus is disclosed to the public, with a time lag) and since each individual is negligible within the consensus, it is difficult to claim that, for reasons which are inherent to speculative games, individuals might not reveal their «true» opinion. For all these reasons, one can reasonably assume that the expectations provided by the respondent experts are representative of market expectations. Considering the panel of experts, it can be noted that about half of the respondents remain unchanged over the period. The turnover in the other half can therefore lead to a bias due to a lack of homogeneity in the average responses over time. However, this bias can be considered as being negligible regarding the dispersion of the opinions. Indeed, the coefficient of variation (i.e., at time $t$, the ratio of the standard-deviation of the responses to their mean) of experts' 3-month ahead interest rate forecasts fluctuates around an average of 0.067 . This implies that the dispersion of individual expectations is limited enough (i.e. the coefficient of variation strongly lower than 1) to assume that no serious statistical problem arises from the aggregation of forecasts, so that the "consensus" values can be viewed as reflecting the representative agent's expectations.

The CE requires a very specific day for the answers. As a rule, this day is the same for all respondents. ${ }^{16}$ Accordingly, we consider the 3-month and 6-month maturity interest rates ${ }_{3} r_{t}$ and ${ }_{6} r_{t}$ released at the same day as $E_{t}\left({ }_{3} r_{t+3}\right)$. Actual values of the 3-month bills rate are directly published in the CE bulletin while interest rates for the 6-month maturity are extracted from the Board of Governors of the US Federal reserve System at a daily frequency.

\footnotetext{
15 Notice that the notion of informed agents does not imply that these agents form rational expectations. Notably, short rate forecasters may have underestimated the importance of the signals emanating from Federal Reserve's quantitative easing announcements at the zero-lower bound (Bauer and Rudebush, 2014). These biased expectations explain that they may have faced "peso effects" in such turmoil periods and this is consistent with the widespread evidence provided by the literature that interest rate expectations are not rational (see introduction). Consequently, it should be understood that market participants make their best decisions on the basis of their biased expectations.

16 This day is the first Monday of the month until March 1994, and the second Monday since April 1994, except the closed days (in this last case, the survey is dated at the following day). The effective horizons however always remain equal to 3 and 12 months. If, for instance, the answers are due on the 3rd of May (which was the case in May 1993), the future values are asked for August 3, 1993 (3 months ahead expectations) and for January 3, 1994 (12 months ahead expectations). The individual responses are then concentrated on the same day.
} 


\subsection{Stylized facts : the term spread, the expected change in interest rate and the risk premium}

The term spread has classically two components that are the expected change in interest rate and the risk premium. Consider the tautology ${ }_{6} r_{t}-{ }_{3} r_{t}=\frac{1}{2}\left[E_{t}\left({ }_{3} r_{t+3}\right)-{ }_{3} r_{t}\right]+\frac{1}{2} \phi_{M t}$ with $\phi_{M t}=2{ }_{6} r_{t}-E_{t}\left({ }_{3} r_{t+3}\right)-{ }_{3} r_{t}$. Using our data, the term spread ${ }_{6} r_{t}-{ }_{3} r_{t}$ and its two components $\frac{1}{2}\left[E_{t}\left({ }_{3} r_{t+3}\right)-{ }_{3} r_{t}\right]$ and $\frac{1}{2} \phi_{M t}$ are displayed in Figure 1 ; it can be seen that both vary around zero with comparable magnitudes. Table 1 shows that the spread is equally correlated with the expected change and the risk premium, but that these two components are weakly correlated between each other, implying that they are complementary to explain the term spread. In fact, the risk premium represents more than half of the variability of the spread. Of course, as long as the ex-ante market risk premium $\phi_{M t}$ is not explained by a structural model, the term structure ${ }_{6} r_{t}-{ }_{3} r_{t}$ remains also unexplained. ADF tests have shown that the spread and its two components are stationary at the $1 \%$ level of significance, while the Breusch-Godfrey serial correlation LM test indicated that they are all three autocorrelated, which suggests the existence of deterministic factors. ${ }^{17} 18$ Especially, the risk premium fluctuates around zero (mean=-0.02) between a maximum of $1.06 \%$ per year and a minimum of $-0.82 \%$ with a standard-error of $0.26 \%$; the proportions of positive, negative and zero values are respectively $42 \%, 54 \%$ and $4 \%$. In particular, the steep rise of the premium observed in 1994 (see Figure 1) can be viewed as a result of the restrictive policy pursued by the Fed, who sharply raised the discount rate. This dissuaded commercial banks from borrowing money, which in turn decreased the available credit and lending activity to the economy. The induced liquidity shortage have plunged investors into counterparty (liquidity) risk exposure and prompted them to require a higher risk premium to offset the risk of capital loss. The risk premium also exhibits a substantial increase during the 2008 financial crisis. The premium dampens during 2009 and remains around zero since then, which is likely due to the Federal Reserve's forward guidance of the short term interest rates at the post-2008 period that led to lower the uncertainty in expectations and thus to shrink risk premium. We can also argue that the risk

\footnotetext{
${ }^{17}$ These tests are not reported but are available upon request.

${ }^{18}$ In this paper we only are concerned with the determination of the risk premium by proposing a short term autoregressive adjustment model towards the required premium. The autoregressive feature of the expected change component has been explained by Prat and Uctum (2018) using backward-looking expectation rules.
} 
premium may have been reduced as a result of the additional liquidity resulting from unconventional policies conducted by the Fed at the ZLB.

Table 1. Correlations between the term spread and its two components

\begin{tabular}{cccc}
\hline & Spread & Expected change & Risk premium \\
& ${ }_{6} r_{t}-{ }_{3} r_{t}$ & $E_{t}\left[{ }_{3} r_{t+3}\right]-{ }_{3} r_{t}$ & $\phi_{M t}$ \\
\hline${ }_{6} r_{t}-{ }_{3} r_{t}$ & 1.00 & 0.75 & 0.78 \\
$E_{t}\left[{ }_{3} r_{t+3}\right]-{ }_{3} r_{t}$ & & 1.00 & 0.16 \\
$\phi_{M t}$ & & & 1.00 \\
\hline
\end{tabular}

Figure 1. Term structure of the 6- and 3-month T-Bill rates: spread, expected change in the 3-month rate and risk premium

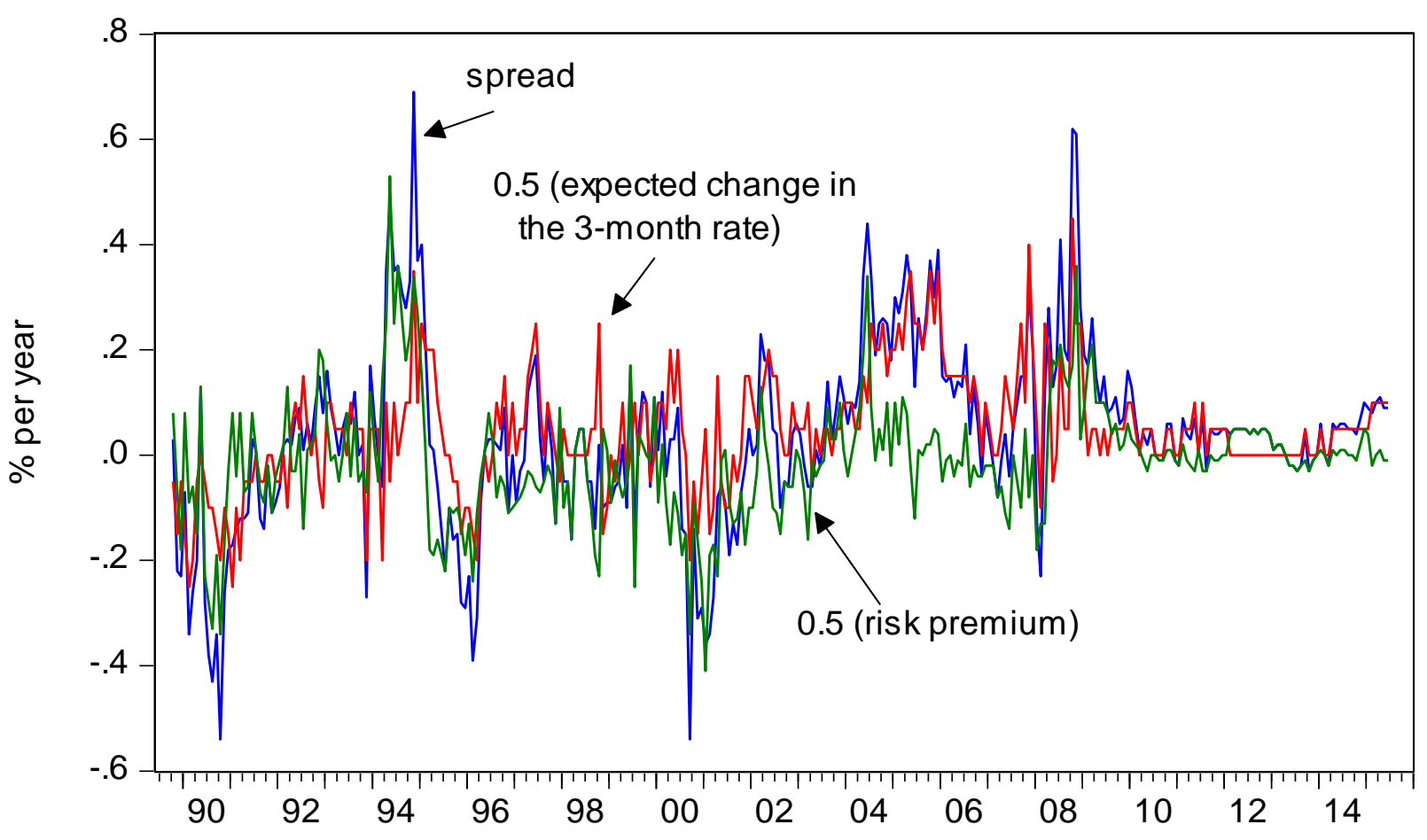

\section{Empirical issues}

4.1 Specifying the unobservable variables and the time-varying parameter model 
To make the structural equation (18) along with Eq.(16) operational, some additional assumptions must be formulated concerning the expected variance $V_{t}=\operatorname{Var}_{t}\left({ }_{3} r_{t+3}\right)$, the expected covariance $\operatorname{Cov}_{t}=\operatorname{Cov}_{t}\left({ }_{3} r_{t+3}, \pi_{t+3}\right)$, the amounts ${ }_{3} N_{t}$ and ${ }_{6} N_{t}$ of the face values of the claims in 3-and 6-month T-Bills respectively, the share of the 6-month asset in the portfolio $\omega_{t}$ and the time-varying weight $\lambda_{t}$.

The expected variance of the 3-month interest rate was estimated using several alternative specifications such as the inter-day variance during the last week or during the last month (and their monthly lagged values), the rolling variance of ${ }_{3} r_{t}$ over alternative windows of 1 to 9 month widths, an unrestricted weighted average of the past values of the quadratic change in ${ }_{3} r_{t}$, and an ARCH approach. Only the latter approach, namely an AR(1)-GARCH(1,1) process, led to finding a measure of $\widehat{V}_{t}$ that allowed validating our structural model. ${ }^{19}$ Note that using the expected conditional variance operator at both sides of the AR(1) mean equation, we get $\hat{V}_{t}=\operatorname{Var}_{t}\left({ }_{3} r_{t+1}\right)=\operatorname{Var}_{t}\left(\hat{u}_{t+1}\right)$, since $\operatorname{Var}_{t}\left({ }_{3} r_{t}\right)$ is zero. This is an intuitive result as it implies that the risk premium depends on the expected variance of the unpredictable component of the short rate only, while the predictable component has naturally no impact. Moreover, the result that the slope coefficient in our $\mathrm{AR}(1)$ equation is insignificantly different from one leads to define the unpredictable component of the short rate $\hat{u}_{t+1}$ as the ex-post change in the short rate $\Delta_{3} r_{t+1}$. Reporting into the relationship above, it can be seen that the expected variance of ${ }_{3} r_{t+1}$ identifies to the expected variance of the change in ${ }_{3} r_{t+1}$. This issue is worth mentioning as it will be useful in determining the expected covariance.

${ }^{19}$ Our estimated AR(1)-GARCH(1,1) model is as follows: ${ }_{3} r_{t}=1.00{ }_{3} r_{t-1}+\hat{u}_{t}, \quad u_{t} \sim \operatorname{GED}\left(0, \sigma_{t}^{2}\right)$ $(0.001)$

$\hat{\sigma}_{t}^{2}=2.8510^{-5}+0.45 \hat{u}_{t-1}^{2}+0.52 \hat{\sigma}_{t-1}^{2}, \bar{R}^{2}=0.99$, Ljung-Box $\mathrm{Q}(2) \mathrm{p}$-value=0.18. We first conducted $\left(3.6310^{-6}\right) \quad(0.05) \quad(0.02)$

the test assuming that errors $u_{t}$ are Gaussian with symmetric (GARCH, GARCH-in-mean) or asymmetric (EGARCH, TGARCH) effects. All specifications were systematically rejected regarding the estimates of the conditional variance, along with the normality assumption of $u_{t}$ 's. We found no better results using Student's distribution. A general error distribution (GED) is then assumed in our mean equation (see the model above), where the intercept and orders higher than 1 were found to be insignificant and where no residual autocorrelation was detected. Concerning the variance equation, none of the GARCH-in-mean, EGARCH and TGARCH variants was identified. Following Bond and Satchell (2006), asymmetric effects in the form of dominant effects of negative shocks on the conditional variance can be attributed to loss aversion behaviour. Our strong evidence of no asymmetry tends to show that T-Bills market investors are not loss averse. 
The expected covariance $\operatorname{Cov}_{t}$ between the future 3-month interest rate and upcoming inflation has been assessed by calculating the rolling covariance between the levels of the two variables over alternative windows of widths ranging from 1 to 9 months. However, none of these attempts led to good fits of the structural state-space model. Better results were obtained using a covariance involving the changes in the two variables rather than their levels. We must then show that this specification of the expected covariance is still consistent with our theoretical model where the short rate and inflation rate are expressed in levels. Similarly to the short interest rate, we found that an $\mathrm{AR}(1)-\mathrm{GARCH}(1,1)$ process fitted best inflation data, where the slope was not significantly different from one and where no residual autocorrelation was present. Under these conditions, given that an autoregressive time-pattern characterizes both variables, it can be straightforwardly shown that the expected covariance of the short term rate and the rate of inflation identifies to the expected covariance of the changes in the two variables. Here again, only the unpredictable components of the levels of the short term rate and the rate of inflation are effective in determining the required premia. We then computed the rolling covariance (denoted ${ }_{k} \operatorname{Cov}_{t}$ ) of the changes in the two variables using a window width of $k$ months and calculated the expected covariance as the weighted average of actual and past values of these rolling covariance terms, that is $\operatorname{Cov}_{t}=\sum_{i=0}^{m} b_{i} \cdot{ }_{k} \operatorname{Cov}_{t-i k} / \sum_{i=0}^{m} b_{i}$ with $b_{0}=1$. Parameters $k, m$ and $b_{i}$ were determined in the course of the estimation of our risk premium model and optimal values were found for $k=3$ and $m=2$. The expected covariance is simplified as:

$$
\operatorname{Cov}_{t}=\frac{{ }_{3} \operatorname{Cov}_{t}+b_{1} \cdot{ }_{3} \operatorname{Cov}_{t-3}+b_{2} \cdot{ }_{3} \operatorname{Cov}_{t-6}}{\left(1+b_{1}+b_{2}\right)}
$$

We now turn to the representation of the amount of face values in 3- and 6-month TBills. By definition, we posit ${ }_{\tau} N_{t}={ }_{\tau} n_{t} F$ and ${ }_{2 \tau} N_{t}={ }_{2 \tau} n_{t} F$ in Eq.(6), where ${ }_{\tau} n_{t}$ and ${ }_{2 \tau} n_{t}$ refer to the number of securities outstanding and $F$ to their face value. Because only the total amount $T B_{t}$ of the outstanding T-bills expressed at market price and in current USD is available (source: Datastream), we examined several assumptions. A first approach was to suppose that each of the face value amounts ${ }_{3} N_{t}$ and ${ }_{6} N_{t}$ is proportional to the total face value amount of the T-Bills measured by $N_{t}=d_{o}\left(1+\bar{r}_{t}\right) T B_{t}$, where $d_{o}\left(1+\bar{r}_{t}\right)$ represents the reverse of the average market price of the T-Bills, $d_{o}=1 / F$ and where 
$\bar{r}_{t}=\left({ }_{1} r_{t}+{ }_{3} r_{t}+{ }_{6} r_{t}+{ }_{12} r_{t}\right) / 4$ represents the average market price of T-Bills across maturities. A second approach consisted in representing each of ${ }_{3} N_{t}$ and ${ }_{6} N_{t}$ by a constant plus a polynomial trend (up to the degree 5). When introduced in Eq.(18), the constant term was found to be significant but the trend polynomials were drastically rejected as a result of preliminary estimations, which then strongly suggest that ${ }_{3} N_{t}$ and ${ }_{6} N_{t}$ should be represented by constants, say, ${ }_{3} N_{o}$ and ${ }_{6} N_{o} .{ }^{20}$ We thus posit ${ }_{3} N_{t}={ }_{3} N_{o}$ and ${ }_{6} N_{t}={ }_{6} N_{o}$, which also implies:

$$
{ }_{6} N_{0} /{ }_{3} N_{0}=\alpha
$$

Model (18) is designed to represent the change in the deviation between observed and required risk premia for the 3- and 6-month maturities of debt. These maturities are, with the 1 and 12-month ones, the most prominent maturities in the T-Bills market. However, the 1 and 12-month maturities can impact the 3 and 6 month market premium because of the market interdependences between interest rates of different maturities. A rise in the 1- and/or 12month rate(s) would prompt market participants to purchase the corresponding asset(s) by selling assets of other maturities, including the 3- and the 6-month ones. The resulting increase in the 3-and 6-month rates would drive up the market observed premium (11) ${ }_{6} r_{t}$ being twice as much weighted as ${ }_{3} r_{t}$ and the discrepancies between the two rates being small, the former rate's effect would dominate the latter's one). On the other hand, the rise in both interest rates would shrink the desired market risk premium (16). ${ }^{21}$ From these opposite effects on observed and required premia would result a widening of their deviation. To account for such exogenous effects, we introduced in the short term dynamics equation (18) the changes in the 1-month rate and in the 12-month rate. Only the latter, namely

\footnotetext{
${ }^{20}$ To provide some insight to these results, note that the total amount at the market price of the outstanding Tbills can be written as $T B_{t}=N_{t} /\left(1+\bar{r}_{t}\right)=N_{0} /\left(1+\bar{r}_{t}\right)+\left(N_{t}-N_{0}\right) /\left(1+\bar{r}_{t}\right)$; we run the regression $T B_{t}=\hat{c}_{1} /\left(1+\bar{r}_{t}\right)+\hat{c}_{o}+\hat{e}_{t}$ where $\hat{c}_{1}$ represents the estimated value of $N_{0}$ while $c_{o}+\hat{e}_{t}$ stands for $\left(N_{t}-N_{0}\right) /\left(1+\bar{r}_{t}\right)$. Hence, $\left(\hat{c}_{o}+\hat{e}_{t}\right)\left(1+\bar{r}_{t}\right)$ proxies the dynamic component $N_{t}-N_{0}$. Regarding the ADF test, this component was found to be stationary at the $5 \%$ level of significance, hence suggesting that $N_{t}$ can be supposed to be stationary. This implies that the hypotheses of constant values for the mean and the variance of $N_{t}$ are acceptable.

${ }^{21}$ It can be seen, from Eq.(16), that an increase in both interest rates exert an opposite effect on the term which multiplies $V_{t}$, while the average value of the quantity $\left(2 \lambda_{t}-1\right) \operatorname{Cov}_{t}$ over the period is found to be close to zero. The total effect on the required premium should therefore be negative.
} 
$\Delta_{12} r_{t}={ }_{12} r_{t}-{ }_{12} r_{t-1}$, appeared to be significant. ${ }^{22}$ We therefore use $\Delta_{12} r_{t}$ to capture the market interdependence effect whose expected impact $\delta$ on the deviation between observed and required premia has just been seen to be positive.

Reporting the proportionality condition (20) into the required market premium (16), adding $\Delta_{12} r_{t}$ into Eq.(18) and rearranging the latter, we get the following equation of the twohorizon risk premium to be estimated :

$$
\phi_{M, t}=\phi_{M, t}^{*}+\gamma\left(\phi_{M, t-1}-\phi_{M, t-1}^{*}\right)+\sum_{q=1}^{m} a_{q} \Delta\left(\phi_{M, t-q}-\phi_{M, t-q}^{*}\right)+\delta \Delta_{12} r_{t}+\zeta_{t}
$$

where $\gamma=1-\kappa$ and $\phi_{M, t}^{*}=\rho_{3} N_{0}\left\{V_{t}\left[\left(1-\lambda_{t}\right) /\left(1+{ }_{3} r_{t}\right)+\alpha \lambda_{t} /\left(1+{ }_{6} r_{t}\right)^{2}\right]\right.$

$$
+\left(2 \lambda_{t}-1\right) \operatorname{Cov}_{t}\left(1 /\left(1+{ }_{3} r_{t}\right)+\alpha /\left(1+{ }_{6} r_{t}\right)^{2}\right\}
$$

The time-varying weight $\lambda_{t}$ is an unobservable variable reflecting the degree of preference in the 3-month horizon relative to the 6-month horizon. We assume that $\lambda_{t}$ follows an $\operatorname{AR}(1)$ process. $^{23}$

$$
\lambda_{t}=\lambda_{o}+\theta \lambda_{t-1}+\eta_{t}
$$

where $\eta_{t}=N\left(0, \sigma_{t}\right)$ and $E\left(\eta_{t}, \zeta\right)=0$.

We can now estimate our model in the form of a two equations state space model, where Eq. (21) defines the measurement (or signal) equation while Eq.(22) stands for the state equation. This model with a time varying coefficient is estimated using Kalman filtering (Harvey (1992), Hamilton (1994)). The initial value of $\lambda_{t}$ has been set by a grid search so as to minimize the information criteria (AIC, Schwarz and Hannan-Quinn). Because we are interested in a structural interpretation of the model, the values of the measurement and state variables are calculated at each time using the whole sample of observations (smoothed inference) rather than only past observations (filtered inference).

\subsection{Estimating the state-space model}

\footnotetext{
${ }^{22}$ Because changes in 1 - and 12 month T-Bills rates are substantially correlated $\left(\mathrm{R}^{2}=0.70\right)$, it is not surprising that only one of the two maturities is found to be significant.

${ }^{23}$ Higher orders did not appear to better fit the data. We also attempted at introducing in the state equation changes in the expected values of inflation and of the GDP growth provided by the same surveys. All the variants were found to be insignificant.
} 
Table 2 provides in the second column the estimates of our state-space model represented by the measurement equation (21) and by the state equation (22) over our sample period. We accounted for the overlapping bias resulting from the difference between our 3month expectation horizon and the monthly frequency of observations by introducing a second order (horizon time-span minus 1) moving average (MA) specification for the residuals (Hansen and Hodrick, 1980). The coefficients $a_{q}$ of the $\Delta z_{t-q}$ terms were found to be insignificant and were removed from the final adjustment, while the coefficients of the two MA terms were found to be significant, implying that our estimates would have been biased if the overlapping problem was not accounted for.

Table 2. Kalman filter estimation results

\begin{tabular}{|c|c|c|}
\hline Sample & $\begin{array}{c}\text { Aug. } 1990-\text { May } 2015 \\
(T=298)\end{array}$ & $\begin{array}{c}\text { Aug. } 1990-\text { Dec. } 2008 \\
(T=221)\end{array}$ \\
\hline \multicolumn{3}{|c|}{ Measurement equation } \\
\hline$\rho_{3} N_{o}$ & $19.31 * * *(2.65)$ & $19.49 * * *(3.42)$ \\
\hline$\alpha$ & $1.52 * * *(0.50)$ & $1.58 * *(0.63)$ \\
\hline$\delta$ & $0.41 * * *(0.03)$ & $0.41 * * *(0.03)$ \\
\hline$\gamma$ & $0.66 * * *(0.04)$ & $0.67 * * *(0.05)$ \\
\hline$b_{1}$ & $0.86 * * *(0.18)$ & $0.78 * *(0.34)$ \\
\hline$b_{2}$ & $0.37 * *(0.18)$ & $0.35(0.35)$ \\
\hline MA(-1) & $-0.24 * * *(0.07)$ & $-0.25 * * *(0.08)$ \\
\hline $\mathrm{MA}(-2)$ & $0.16 * * *(0.06)$ & $0.16^{* *}(0.07)$ \\
\hline$k_{M}$ & $-4.18^{* * *}(0.06)$ & $-3.91 * * *(0.08)$ \\
\hline \multicolumn{3}{|l|}{ State equation } \\
\hline$\lambda_{o}$ & - & - \\
\hline$\theta$ & $0.99 * * *(0.005)$ & $0.99 * * *(0.004)$ \\
\hline$k_{S}$ & $-6.10 * * *(1.01)$ & $-6.91 * * *(1.54)$ \\
\hline $\bar{R}^{2}$ & 0.71 & 0.70 \\
\hline $\bar{R}_{D}^{2}$ & 0.57 & 0.56 \\
\hline$Q^{*}(4)$ & 10.06 & 4.73 \\
\hline$h H^{*}(h)$ & 35.01 & 46.20 \\
\hline$F_{\text {RESET }} p$-value & 0.06 & 0.12 \\
\hline$A I C$ & -1.28 & -1.02 \\
\hline$S C$ & -1.27 & -1.00 \\
\hline$H Q C$ & -1.28 & -1.01 \\
\hline$L$ & 192.03 & 113.43 \\
\hline
\end{tabular}


Notes - Numbers in parentheses are the standard deviations. The estimated state-space model is given by the system made by the measurement equation (21) and the state equation (22). The sample period in column 2 is the full sample, the one in column 3 is the sub-sample excluding the zero-lower bound of short term interest rates. The constant $\rho_{3} N_{o}$ was first assessed at the value of a grid search corresponding to the lowest information criteria and re-estimated while the other parameters were set to their estimated values to compute its standard-deviation. The estimated intercept of the state equation being insignificantly different from zero, final estimates are obtained by setting $\lambda_{o}=0$. To ensure positivity, the unconditional variances of $\zeta_{t}$ and $\eta_{t}$ are estimated as $\exp \left(k_{M}\right)$ and $\exp \left(k_{S}\right)$, respectively. $R_{D}^{2}$ is a measure of goodness of fit which compares to a random walk with drift (Harvey, 1992). AIC, SC and HQC stand for Akaike, Schwarz and Hannan and Quinn information criteria, while $L$ is the log-likelihood value. The asymptotic critical values of the $Q^{*}$-statistic follow a $\chi^{2}$ with $\sqrt{298}-10=7$ d.o.f. at the full sample and $\sqrt{221}-10=5$ d.o.f. at the subsample and are $(12.0,14.1,18.5)$ and $(9.2,11.1,15.1)$ at the $(10 \%, 5 \%, 1 \%)$ levels of significance, respectively. The asymptotic critical values of the $h H^{*}(h)$ statistic follow a $\chi^{2}$ with $h=298 / 3=99$ d.o.f. at the full sample and $h=221 / 3=74$ d.o.f. at the subsample and are $(118,124$, $136)$ and $(85.5,90.5,100)$ at the $(10 \%, 5 \%, 1 \%)$ levels of significance, respectively. $F_{\text {RESET }}$ is the $\mathrm{F}$ test for the null that the powers of order up to 3 of the regressors of $\phi_{M, t}-\hat{\phi}_{M, t}^{*}$ in $\operatorname{Eq}(21)$ jointly have zero slopes.

The two-horizon risk premium model fits well the data over our sample period (second column) with all parameters significant at all conventional levels. The parameter $\gamma$ associated with the past deviation between offered and required market risk premia is found to be 0.66 , implying that the coefficient of the error correction term in Eq.(18) is $\kappa=1-\gamma=0.34$. This result shows evidence that the deviation between market risk premia is mean-reverting and suggests that this deviation subsides with a half-life of 1.67 month. ${ }^{24}$ The estimated value of the ratio $\alpha$ indicates that the amount of the 6-month Bill is 1.5 times the amount of the 3 month Bill. The estimated constant $\varphi_{3} N_{o}$ and the coefficient $\delta$ of the change in the 12month T-Bill rate are positive, as expected. ${ }^{25}$ The estimates $b_{1}=0.86$ and $b_{2}=0.37$ imply that the expected covariance (20) is determined by a weighted average of actual and past observed covariances with decreasing weights, which is rather intuitive. We now discuss the inference of the state variable $\lambda_{t}$ (Eq.(22)). The intercept $\lambda_{o}$ was removed in the final estimation since it failed to be significant. The estimated slope of the lagged value, $\theta$, is found to be 0.99 , indicating that $\lambda_{t}$ is stationary (although, regarding the standard error of the

\footnotetext{
${ }^{24}$ Denote now by $z_{t}$ the estimated deviation. It follows from (20) that $z_{t}=\hat{\gamma} z_{t-1}+\hat{\delta} \Delta_{12} r_{t}\left(\hat{a}_{q}=0 \forall q\right)$. It can be shown, at horizon $h$, that $\tilde{z}_{t+h}=\hat{\gamma}^{h} \tilde{z}_{t}$, where $\tilde{z}_{t+s}(s=\{0, h\})$ is the deviation adjusted for the (cumulative) effect of the change(s) in the 12-month T-Bills rate up to $s$. The half-life of this adjusted deviation is the horizon $h$ at which the deviation is reduced by half (i.e. $\hat{\gamma}^{h}=1 / 2$ ), which yields $h=\log (1 / 2) / \log (\hat{\gamma})$.

${ }^{25}$ Note that the expected impact, as described in section 4.1, of $\Delta_{12} r_{t}$ on $\phi_{M, t}^{*}$ would suggest that these two variables are collinear in Eq.(21). However, the inclusion of $\Delta_{12} r_{t}$ as a short term adjustment variable did not cause any problem of collinearity since it is found to be weakly correlated with all regressors (the coefficients were around -0.10 with $\phi_{M, t}^{*}$ and $\phi_{M, t-1}-\phi_{M, t-1}^{*}$ and near-zero with $\left.\Delta\left(\phi_{M, t-i}-\phi_{M, t-i}^{*}\right), i=0, \ldots 4\right)$.
} 
estimate, random walk behavior appears as a limit case). ${ }^{26}$ The time-pattern of the estimated values of $\lambda_{t}$ lies between 0 and 1 (Figure 2), which means that, at any time, both horizons play a role in the determination of the risk premium. Moreover, the limit values 0 and 1 stand outside the $95 \%$ confidence interval during almost all the period for the former and most of the period for the latter, implying that generally they cannot be statistically accepted. This innovative result contradicts the invariant hypothesis of the literature according to which $\lambda_{t}=1 \forall t$ and consequently that the short term rate is the riskless rate. Further to our result that the weight is different from 1, Figure 2 suggests that $\lambda_{t}$ is time-varying. This is seen from the evidence that, on the one hand, no constant value can unchangingly be included in the confidence intervals along the sample period. On the other hand, $\lambda_{t}$ swings around a mean of 0.65 , which reflects a dominance of the 3-month horizon vis-à-vis the 6-month horizon by two-thirds / one third on average. While the market was dominated by the 3-month horizon in the beginning of the period and at the end of 2000s, the 3- and 6-month horizons seem to be balanced between late 1990's and early 2000s and tend towards a balanced distribution since the 2008 financial crisis.

Figure 2. Degree of preference for the 3-month horizon (state variable $\lambda_{t}$ )

\footnotetext{
${ }^{26}$ Recall that the preference parameter $\lambda_{t}$ is generated following an AR(1) process in a non-linear model and its estimated slope $\hat{\theta}=0.99$ lies within the $5 \%$ confidence interval $[0.98,1]$. This interval is remarkably narrow around the mean, reflecting the reliability of the estimate. Although it includes unity on the very edge of the interval, the probability that unity is the true slope is much dominated by the one that the mean is the true value. Note that even though $\hat{\theta}$ equals unity, because $\lambda_{t}$ is a weighting coefficient $\left(0 \leq \lambda_{t} \leq 1 \forall t\right)$ it exerts no nuisance effect on the consistency of the model. Indeed, as shown by Nicolau (2002), a magnitude which behaves like a random walk is not a true random walk if it is bounded between upper and lower values, because a true random walk goes asymptotically to infinity with probability one. The author demonstrates that such bounded random walk processes can have stationary distributions.
} 


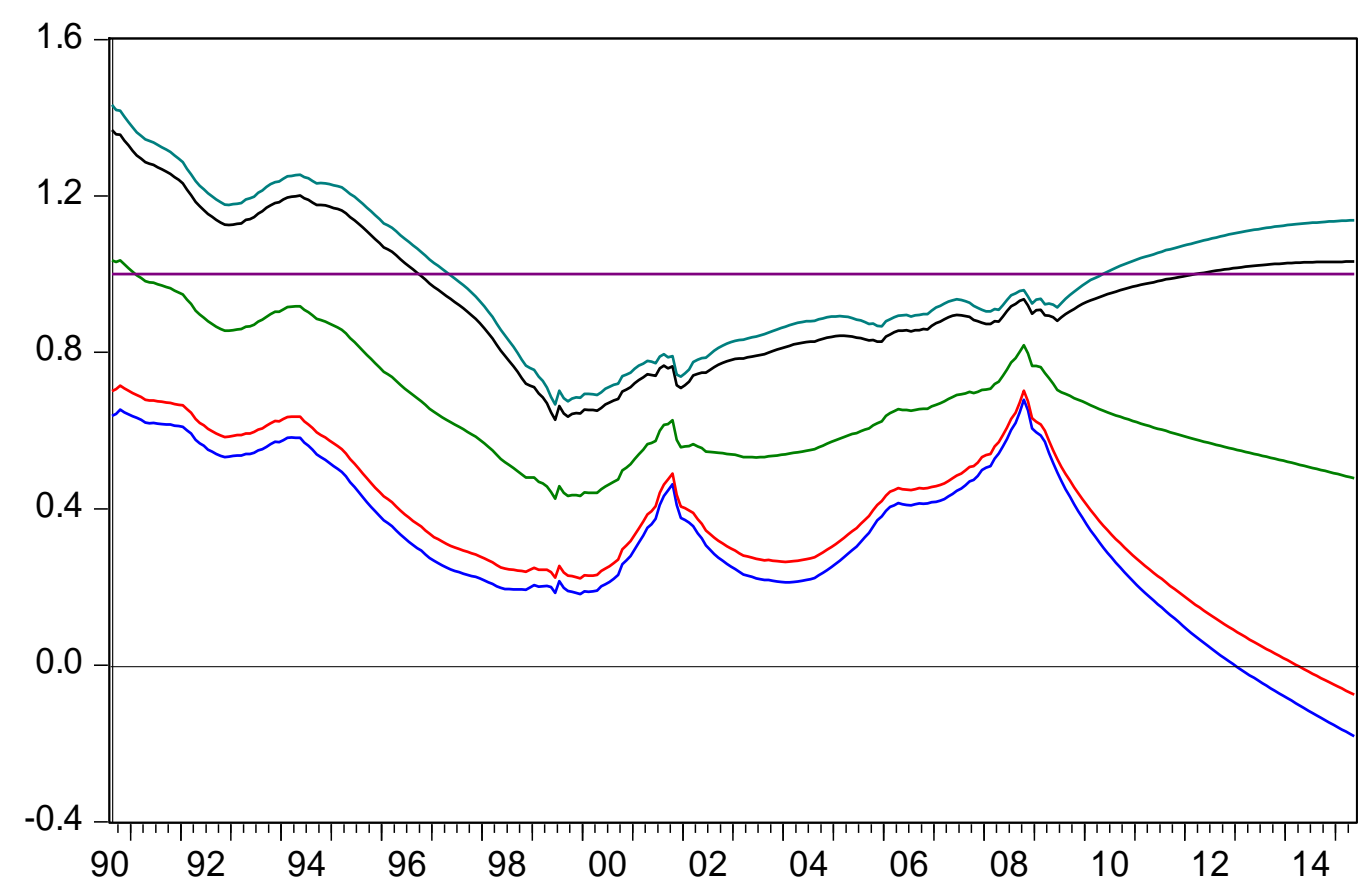

Notes - The central line represents the smoothed estimated values of the state variable $\lambda_{t}$; the outer and inner intervals are calculated as $\lambda_{t} \pm 1.96 S D_{t}$ and $\lambda_{t} \pm 1.645 S D_{t}$ corresponding to the $95 \%$ and $90 \%$ confidence bounds, respectively ( $S D_{t}$ : conditional standard deviation of $\lambda_{t}$ ).

The post-2008 period is characterized by a collapse in the short term US interest rates to near-zero values, giving rise to a situation of liquidity trap and the implementation of unconventional monetary policies by the Federal Reserve. To check whether this zero-lower bound of short term interest rates have distorted the estimates over the period, we also performed the Kalman filter estimation over the sub-period excluding the ZLB (i.e., over the sub-period 08/1990-12/2008). ${ }^{27}$ The results are provided in column 3, Table 2. A Wald test of equality between estimates from this sub-period and those from the full sample has shown that the null of equality very strongly failed to be rejected at the $5 \%$ level, indicating that no significant bias has resulted from the ZLB. Of course, this finding does not mean that agents' behavior have remained unchanged at the ZLB compared to the preceding sample period. All what can be said is that in view of observed and fitted values of the risk premium over the full period, the proposed model provides a good representation of the risk premium at the ZLB (see Figure 4 below). Note that we cannot estimate the model over this particular period given

\footnotetext{
${ }^{27}$ Among the unconventional policies carried on at this period, quantitative easing was designed to influence long term interest rates to stimulate investments. However, this policy may in turn have produced possible impacts on risk premia at the shorter end of the term structure by, for example, encouraging some agents to decide to hoard liquidities. This enhances the relevance of considering the sub-period excluding the zero lower bound.
} 
the low number of observations and regarding the nonlinear structure of model (21) along with Eq.(22). However, to formally check the validity of the model at the ZLB, we carried out over this specific period diagnostic tests using the residuals that we obtained from the estimation over the whole sample. We found that at the ZLB, Kalman filter residuals remain serially uncorrelated and non-heteroskedastic at the 5\% level. ${ }^{28}$ Among different studies examining the term structure relationship during the ZLB period, our results compare with those of shadow-rate models (Christensen and Rudebusch, 2016; Ichiue and Ueno, 2013; Kim and Singleton, 2012) regarding their performance in estimating risk premia. Because they respect the ZLB, shadow rate models allow a realistic decomposition of the long rate into expectations components and the risk premium, contrary to affine models which lead to underestimate the risk premium due to an unreasonably high estimate of the long term level of the short rate. Our model is not distorted by the low interest rate environment possibly for two reasons. First, it introduces an endogenous time-varying preference parameter for alternative horizons, reflecting wider arbitrage possibilities for investors. Second, due to survey data availability, our risk premium relate to two monetary rates which both are impacted by the unconventional monetary policies conducted by the Federal Reserve over the ZLB. In this context, the observed risk premium should tend to zero because of the slump in observed and expected interest rates. In our model, when the monetary rates are stacked at the lower bound, the expected variance of the short rate and the expected covariance between the short rate and inflation should mechanically collapse. According to Eq.(21), so would do the required risk premium, towards which the market risk premium would then adjust.

The statistical properties of the standardized smoothed residuals of the measurement equation for the full period can be examined by performing appropriate Ljung-Box autocorrelation $Q^{*}$ test and heteroskedasticity $h H^{*}$ test developed by Harvey (1992). The $Q^{*}$ test at the lower panel of Table 2 is a modified version of the standard Portmanteau test; the underlying Ljung-Box statistic follows a $\chi^{2}$ distribution with a $\sqrt{T}-m+1$ degrees of freedom, where $T$ is the sample size and $m$ the number of parameters. According to our test statistics values (with 4 lags), the null of no residual autocorrelation fails to be rejected at all levels of significance. The $h H^{*}$ test compares the sum of squared smoothed standard residuals between two sub-periods defined as the one-third and the two-thirds of the sample period. The

\footnotetext{
${ }^{28}$ Over the sample January 2009 - May 2015 (75 observations), Breusch-Godfrey autocorrelation LM test with 4 lags provided an $F$ statistics value of $1.40(\mathrm{~F}(4,70)=5.70)$ (here Harvey's $\mathrm{Q}^{*}$ test cannot be implemented because of the low number of observations, leading to a negative d.o.f.), while Harvey's heteroscedasticity $\mathrm{hH}^{*}$ test allowed for a $\mathrm{hH}^{*}$ statistics value of $10.52\left(\chi^{2}=37.7\right.$ for $75 / 3=25$ d.o.f. $)$
} 
asymptotic distribution of the statistic is a $\chi^{2}$ with $T / 3$ d.o.f. According to this test, we can conclude that the null of no heteroskedasticity is not rejected for all levels of significance. Overall, these results suggest that innovations are well-behaved and that the conditions of application underlying the Kalman filter modelling are satisfied (see Stock and Watson (1998), Durbin and Koopman (2001). In particular, the rejection of residual autocorrelation seems to indicate that the linear functional form assumed in the error correction model (18) is supported by the data. To corroborate this result, we first assessed the fitted values of $\phi_{M, t}$ from the reduced form of the system made of Eqs.(21) and (22). We then performed Ramsey's specification error test (RESET) to the reduced linear error correction model to check whether inclusion in the regression equation of the powers of the fitted values of $\phi_{M, t}$ leads to zero coefficients on these power variables. According to the F-test, the null of no influence of power variables failed to be rejected at the $5 \%$ level ( $\mathrm{p}$-value $=0.058$ for the full sample and 0.12 for the sub period ending on december 2008). Furthermore, the autoregressive feature of the preference parameter for the short horizon $\lambda_{t}$ suggests that some underlying factors might be detected. Although the specification of the AR form did not allow for evidencing any observable variables in the course of the estimation of the state-space model (see footnote 23), we carried out an empirical analysis consisting in directly regressing $\lambda_{t}$ on such independent variables. To ensure that our estimates are robust to heteroscedasticity and autocorrelation, we used the Newey-West method and found that more than $50 \%$ of the variance of $\lambda_{t}$ can be represented by the expected rate of inflation and the expected growth in the real GDP, both for the next calendar year, denoted $E_{t} \pi_{y+1}$ and $E_{t} g_{y+1}$, respectively (the data were provided by Consensus Economics). Other variables tested and which appeared to be insignificant whether lagged or not were the uncertainty about future inflation (measured as the expected volatility estimated using a GARCH model), the degree of heterogeneity in interest rates expectations (standard errors of the 3- and 12-month ahead expected values of the three-month rate), the observed inflation rate, the observed real GDP growth rate and the 10-year maturity Treasury bonds yield (or its change). We finally obtain the following regression ( $t$ values in brackets) ${ }^{29}$ :

\footnotetext{
${ }^{29} \mathrm{ADF}$ tests have shown that $E_{t} \pi_{y+1}$ and $E_{t} g_{y+1}$ are stationary at the 5\% level while the stationarity of $\lambda_{t}$ at the same level has been discussed in footnote 26 . We can then conclude that there is no problem of specification due to the degree of integration of the variables.
} 


$$
\lambda_{t}=\underset{(4.11)}{0.40}+\underset{(7.26)}{0.16} E_{t} \pi_{y+1}-\underset{(-2.50)}{0.05} E_{t} g_{y+1}+e_{t} \quad R^{2}=0.558 \quad D W=0.10
$$

where $e_{t}$ is the residual term. When expected inflation for the next year increases, to avoid negative real interest rates at longer horizons agents prefer to shorten their investment horizon, which implies a higher value of $\lambda_{t}$. Conversely, when the expected growth rate in real GDP increases, positive real interest rates are expected at longer horizons, hence encouraging investors to extend their time horizon, which implies a lower value of $\lambda_{t}$. May these outcomes result from arbitrary regressor selection, they enhance the credibility of the estimated dynamics of $\lambda_{t}$ described by the state equation. However, the $D W$ statistic shows that they are strongly auto-correlated, which clearly indicates that factors other than the two identified ones affect the preference parameter.

Figure 3 exhibits the estimated values of the expected covariance between the 3-month rate and inflation $\left(\operatorname{Cov}_{t}\right)$ and of the expected variance of the 3-month rate $\left(V_{t}\right)$, which both are influential factors of the risk premium. It can be seen that these two factors fluctuate with the same order of magnitude. The weak correlation between $V_{t}$ and $\operatorname{Cov}_{t}$ over the period shows that they are complementary in explaining the premium, except during the 2008 financial crisis where they move together with sharp fluctuations before they die out at the zero-lower bound of short term interest rates. Interestingly, these findings are consistent with Filardo and Hofmann (2014) who show that the forward guidance, one of the unconventional monetary policies conducted by the Federal Reserve at the zero-lower bound, led to lower the volatility of expectations about the future path of policy interest rates. 
Figure 3 : Expected variance of the US 3-month interest rate and expected covariance between interest rate and inflation

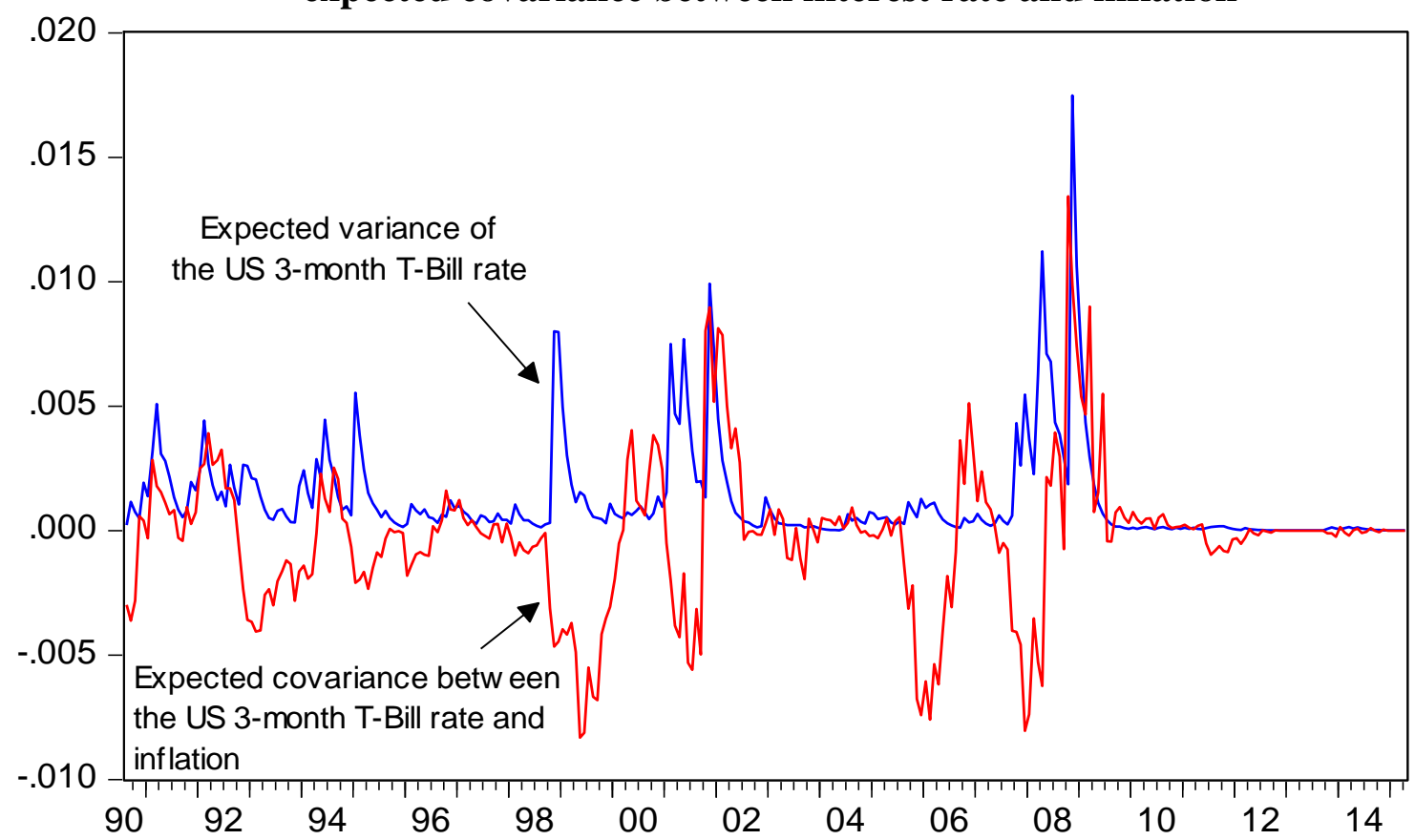

We now examine the ability of our state-space model to describe the risk premium dynamics. Figure 4 compares the "observed" values of the market ex-ante risk premium to the fitted values from the measurement equation (21): the major fluctuations are well reproduced and especially no systematic lags between observed and fitted values can be reported. We further checked the relevance of this fit using Harvey's (1992) modified coefficient of determination $R_{D}^{2}$ that assesses the goodness of the fit with respect to a simple random walk plus drift process. ${ }^{30}$ The $R_{D}^{2}$ value indicates that the residual variance of the signal equation is 0.43 times the one of the random walk model, which implies that our model strongly outperforms the random walk.

\footnotetext{
${ }^{30}$ Harvey's (1992) goodness of fit measure is given by $R_{D}^{2}=1-S S R / \sum_{t=2}^{T}\left(\Delta y_{t}-\overline{\Delta y}\right)^{2}$ where $y_{t}$ and $S S R$ are the dependent variable and the sum of the squared residuals of the measurement equation, respectively. A negative $R_{D}^{2}$ would imply that the estimated model is beaten by a simple random walk plus drift.
} 
Figure 4. Observed and fitted values of the two-horizon ex-ante risk premium

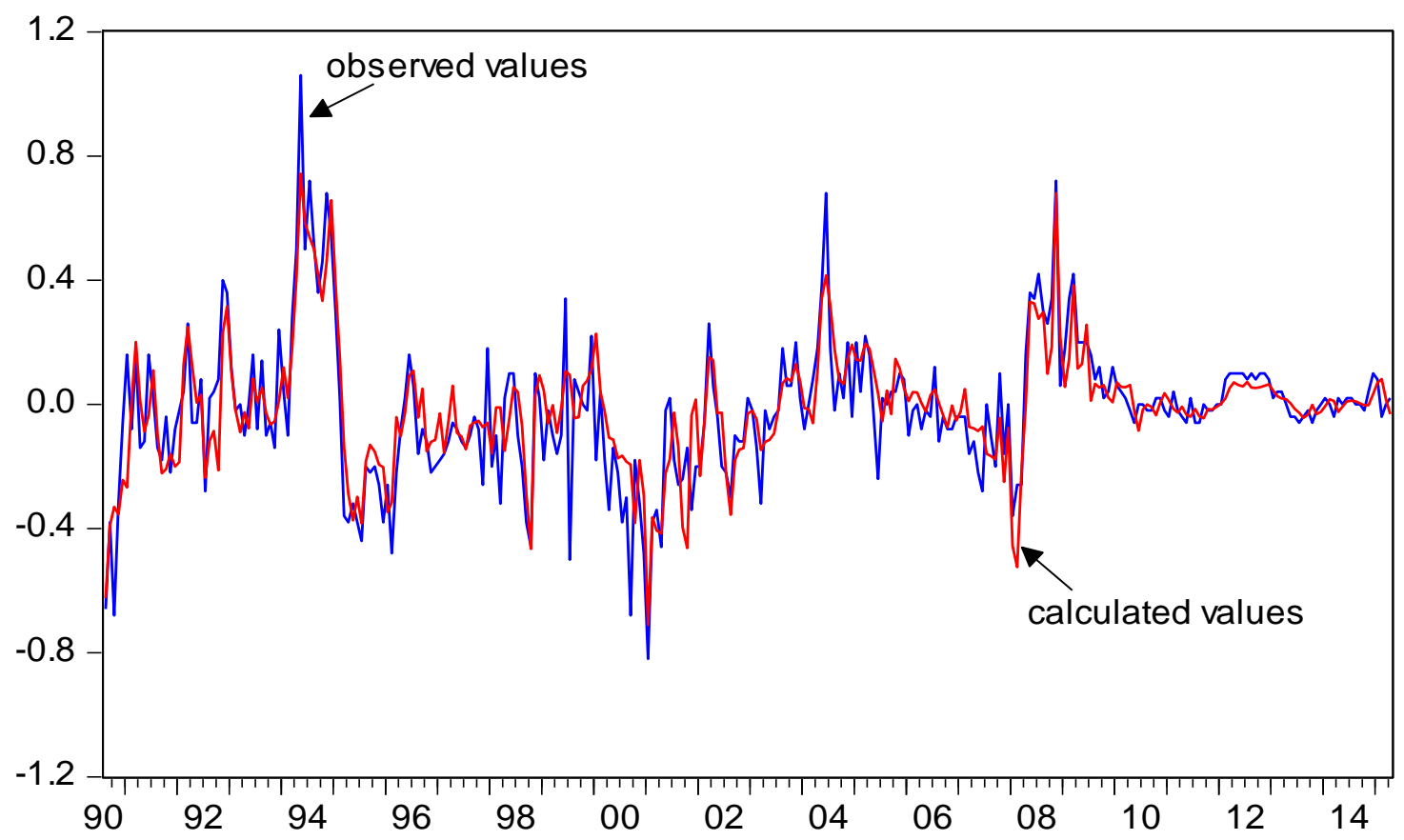

\section{Conclusion}

This article aims at revisiting the standard model of the risk premium, which is a key component of the term structure of interest rates. We propose a new approach relaxing the commonly accepted joint hypothesis that the riskless debt is the one-period maturity claim, while the risky debt is the $n$-period maturity claim $(n>1)$. This joint hypothesis is indeed valid only when the investor wishes to make a one-period investment. When the investor prefers to undertake a $n$-period investment, the riskless rate is the rate on a (zero-coupon) claim whose duration coincides with the investor's horizon.

We consider a representative agent willing to invest both at the 1-period and 2-period horizons and comparing for each horizon the ex-ante market premium with the required value so as to choose between a riskless investment and a risky investment. On theoretical grounds, we find that both the 1- and 2-period risk premia offered by the market can take positive or negative values but are strictly of opposite signs at any time. At the demand side, we calculate the required values of the 1- and 2-period premia as solutions of a portfolio choice model, according to which the representative agent maximizes the expected real value of their future wealth. Contrary to the premium offered, the required premia are not symmetrical although 
they can also take positive or negative values. Because the representative investor considers at any time both horizons, the ex-ante market premium is, at the equilibrium, equal to the weighted average of the 1- and 2-period required premia, where the time-varying weight associated with the 1-period (resp. 2-periods) required premium measures the degree of preference of the market for the 1-period (resp. 2-period) horizon. Our model is thus a more general approach than the standard hypothesis according to which the riskless debt is exclusively the short maturity claim. While our model reduces to the standard model as a special case, it allows measuring the share of the market for which the riskless rate is the short rate and the share for which the riskless rate is the long rate.

By setting one period equal to three months, we use 3-month ahead expected values of the US 3-month Treasury bill rate provided by Consensus Economics surveys and the 3- and 6-month Bill rates to estimate our 3- and 6-month horizon risk premium model over the period November 1989 - May 2015. With these data, we find that the risk premium explains about half of the variance of the spread, which reflects the importance of modeling the risk premium to explain the term structure of interest rates. We estimate our hybrid model of the risk premium with time varying weights using the Kalman filter methodology. Our results strongly invalidate the restrictive hypothesis of the literature that the riskless (risky) rate is always given by the short (long) rate and support the evidence that, at any time, the market refers to both maturities to define the riskless and risky rates with a 3-month maturity weight varying around its mean of 0.65 over the sample period. Moreover, we find evidence that, due to market frictions, the deviations between the offered and required market risk premia are mean-reverting, with a half-life of 1.67 month. Overall, our hybrid two-horizon model fits well the data and suggests that, to describe adequately risky strategies, the market preferences for both short and long horizons must be taken into account when modeling the term structure of interest rates.

\section{References}

Allais M. (1947), Economie et Intérêt, Imprimerie Nationale, Paris

Anderson H.M. (1997), "Transaction costs and nonlinear adjustment towards equilibrium in the US treasury bill markets", Oxford Bulletin of Economics and Statistics, 59, 465-484.

Ang, A., G. Bekaert, and M. Wei (2008), "The term structure of real rates and expected inflation", Journal of Finance, 63, 797-849.

Artus P. (1990), « Primes de risque et taux d'intérêt », Economie et Statistiques, 236, 25-36 
Bauer, M.D., G.D. Rudebush (2014), «The signalling channel for Federal Reserve bond purchases", International Journal of Central Banking, 10, 233-89.

Bauer G.H., A. Diez de los Rios (2012), «Global risk Premiums and the transmission of Monetary Policy", Bank of Canada Review, Summer: 12-20

Baumol, W. (1952), "The transaction demand for cash : an inventory theoretic approach" Quarterly Journal of Economics, 66(4) : 545-56

Black, F. (1995), “Interest Rates as Options,” Journal of Finance, 50(7), 1371-76.

Bond, S.A., S.E. Satchell (2006), “Asymmetry, loss aversion and forecasting”, The Journal of Business, 79(4), 1809-30.

Christensen J.H.E., G.D. Rudebusch (2016), Modeling Yields at the Zero Lower Bound: Are Shadow Rates the Solution?, in Eric Hillebrand, Siem Jan Koopman (ed.) Dynamic Factor Models, Advances in Econometrics, Volume 35, Emerald Group Publishing Limited : 75 125.

Clarke R., H. de Silva, S. Thorley (2002), "Portfolio constraints and the fundamental law of active management", Financial Analysts Journal, 58(5), 48-66

Colletaz G. (1986), «Prévisions explicites de taux d'intérêt en France, : une étude empirique sur la période 1981-1985 », Finance, 7(2), 111-134

Culbertson, J. M. (1957), "The term structure of interest rates", Quarterly Journal of Economics, 71, 489-504.

Dai, Q., K.J. Singleton (2002), "Expectation puzzles, time-varying risk premia, and affine models of the term structure", Journal of Financial Economics, 63, 415-441.

Ding, Z. and R.D. Martin (2017), “ The fundamental law of active management: redux", Journal of Empirical Finance, 43, 91-114.

Duffee, G.R. (2002), "Term premia and interest rate forecasts in affine models", Journal of Finance, 58, 405-43.

Duffie, D., R. Kan (1996), “A Yield-factor Model of Interest Rates,” Mathematical Finance 6, 379-406

Durbin J., S.J. Koopman (2001), Time Series Analysis by Space State Methods, Oxford University Press.

Fama, E.F., R.R. Bliss (1987), "The information in long-maturity forward rates", American Economic Review, 77 (4), 680-692.

Feige E.L., D.K. Pearce (1976), «Economically rational expectations : are innovations in the rate of inflation independant of innovations in measures of monetary and fiscal policy? », Journal of Political Economy, 84(3), 499-522.

Filardo, A., B. Hofmann (2014), "Forward Guidance at the Zero Lower Bound", BIS Quarterly Review, March, 37-53.

Friedman, B.M. (1979), "Interest rate expectations versus forward rates: evidence from an expectations study", Journal of Finance, 34(4), 965-973.

Friedman, B.M. (1980), "The determination of long-term interest rates: implications for fiscal and monetary policies", Journal of Money, Credit and Banking, 12(2), 331-352.

Froot K.A. (1989), "New hope for the expectations hypothesis of the term structure of interest rates", Journal of Finance, 44, 283-305. 
Greer, M. (2003), "Directional accuracy tests of long-term interest rate forecasts", International Journal of Forecasting, 19, 291-298.

Grinold R.C. (1989), "The Fundamental Law of Active Management." Journal of Portfolio Management, 15(3): 30-37.

Grinold, R.C., and R.N. Kahn (2000), "The Efficiency Gains of Long-Short Investing." Financial Analysts Journal, 56(6), 40-53.

Hamilton J.D. (1994), Time series analysis, Princeton University Press, Princeton, New Jersey.

Hansen, L.P., R.J. Hodrick (1980), "Forward exchange rates as optimal predictors of future spot rates: an econometric analysis," Journal of Political Economy, 88, 829-853.

Harvey A.C. (1992), Forecasting, structural time series models and the Kalman filter, Cambridge University Press, Cambridge.

Hicks, J.R. (1946), Value and Capital: An Inquiry into Some Fundamental Principles of Economic Theory, Oxford : Clarendon Press.

Ichiue, H., Y. Ueno (2013), "Estimating term premia at the zero bound: an analysis of Japanese, US, and UK yields", Working Paper 2013-E-8, Bank of Japan

Jawadi F., G. Prat (2012), "Arbitrage costs and nonlinear stock price adjustment in the G7 Countries", Applied Economics, 44 (12), 1561-82.

Jongen, R., W.F.C. Verschoor (2008), "Further evidence on the rationality of interest rate expectations", Journal of International Financial Markets, Institutions \& Money, 18(5), $438-448$.

Kane E.J., B.G. Malkiel (1967), «The term structure of interest rates: an analysis of a survey of interest rate expectations », Review of Economics and Statistics, 49, 343-55.

Kim S.-J. (1997), "Testing the rationality of exchange rate and interest rate expectations", Applied Economics, 29, 1011-1022

Kim, D.H. and K.J. Singleton (2012), "Term structure models and the zero bound: an empirical investigation of Japanese yields", Journal of Econometrics, 170, 32-49.

MacDonald R. (2000), « Expectations formation and risk in three financial markets: surveying what surveys says », Chap. 9 in : F. Gardes and G. Prat (Eds), Price Expectations in Goods and Financial Markets : New Developments in Theory and Empirical Research, EdwardElgar, Cheltenham, UK.

MacDonald R., P. Macmillan (1994), «On the expectations view of the term structure, term premia and survey-based expectations », Economic Journal, 104, 1070-86.

Malkiel, B.G., E.J. Kane (1969), "Expectations and interest rates: a cross-sectional test of the error-learning hypothesis, Journal of Political Economy, 69, 77(4), 453-470.

Modigliani, F., R. Sutch (1966), "Innovations in interest rate policy", American Economic Review, 56, 178-97.

Nicolau, J. (2002), "Stationary processes that look like random walks - The bounded random walk process in discrete and continuous time", Econometric Theory, 18, 99-118.

Prat G., R. Uctum (2010), «Anticipations, prime de risque et structure par terme des taux d'intérêt : une analyse des comportements d'experts », Recherches Economiques de Louvain /Louvain Economic Review, 76(2), 2010, 195-217 
Prat G., R.Uctum (2018), "Do markets learn to rationally expect US interest rates? Evidence from survey data", Applied Economics, 50(59), 6458-6480.

Roll R. (1971), «Investment diversification and bond maturity », Journal of Finance, 26, 5166.

Shiller R.J. (1990), «The term structure of interest rates », in : Eds B.M.Friedman et F.H. Hahn, Handbook of monetary economics, Vol.1, Chap.13, North-Holland, New-York, 627722.

Shleifer A., L.H. Summers (1990), "The noise trader approach to finance”, Journal of Economic Perspectives, 4, 19-33.

Simon, D.P. (1989), "The rationality of Federal Funds Rate expectations: evidence from a survey", Journal of Money, Credit and Banking, 21, 388-93.

Stock J.H., M.W. Watson (1998), “Asymptotically Median Unbiased Estimation of Coefficient Variance in a Time Varying Parameter Model", Journal of the American Statistical Association, 93, 349-58.

Thaler R. (1999), "Mental accounting matters", Journal of Behavioral Decision Making, 12, 183-206.

Tobin J. (1956), "The interest-elasticity of transactions demand for cash", The Review of Economics and Statistics, 38(3), 241-247

Vayanos, D., J.L. Vila (2009), "A preferred-habitat model of the term structure of interest rates”. NBER Working Paper 15487. 